\title{
Altered Intrinsic Pyramidal Neuron Properties and Pathway- Specific Synaptic Dysfunction Underlie Aberrant Hippocampal Network Function in a Mouse Model of Tauopathy
}

\author{
(C) Clair A. Booth, ${ }^{1 *} \oplus^{-}$Jonathan Witton, ${ }^{1 *}$ Jakub Nowacki, ${ }^{2}$ CKrasimira Tsaneva-Atanasova, ${ }^{2,3}$ @Matthew W. Jones, ${ }^{1}$ \\ Andrew D. Randall, ${ }^{1,4}$ and $\odot$ Jonathan T. Brown ${ }^{1,4}$ \\ ${ }^{1}$ School of Physiology and Pharmacology and ${ }^{2}$ Department of Engineering Mathematics, University of Bristol, Bristol BS8 1TD, United Kingdom, ${ }^{3}$ College of \\ Engineering, Mathematics and Physical Sciences, University of Exeter, Exeter EX4 4QF, United Kingdom, and ${ }^{4}$ Institute of Biomedical and Clinical Sciences, \\ University of Exeter Medical School, Hatherly Laboratories, University of Exeter, Exeter EX4 4PS, United Kingdom
}

The formation and deposition of tau protein aggregates is proposed to contribute to cognitive impairments in dementia by disrupting neuronal function in brain regions, including the hippocampus. We used a battery of in vivo and in vitro electrophysiological recordings in the rTg4510 transgenic mouse model, which overexpresses a mutant form of human tau protein, to investigate the effects of tau pathology on hippocampal neuronal function in area CA1 of 7- to 8-month-old mice, an age point at which rTg4510 animals exhibit advanced tau pathology and progressive neurodegeneration. In vitro recordings revealed shifted theta-frequency resonance properties of CA1 pyramidal neurons, deficits in synaptic transmission at Schaffer collateral synapses, and blunted plasticity and imbalanced inhibition at temporoammonic synapses. These changes were associated with aberrant CA1 network oscillations, pyramidal neuron bursting, and spatial information coding in vivo. Our findings relate tauopathy-associated changes in cellular neurophysiology to altered behaviordependent network function.

Key words: GABA; intrinsic properties; place cell; resonance; synaptic plasticity

Significance Statement

Dementia is characterized by the loss of learning and memory ability. The deposition of tau protein aggregates in the brain is a pathological hallmark of dementia; and the hippocampus, a brain structure known to be critical in processing learning and memory, is one of the first and most heavily affected regions. Our results show that, in area CA1 of hippocampus, a region involved in spatial learning and memory, tau pathology is associated with specific disturbances in synaptic, cellular, and network-level function, culminating in the aberrant encoding of spatial information and spatial memory impairment. These studies identify several novel ways in which hippocampal information processing may be disrupted in dementia, which may provide targets for future therapeutic intervention.

\section{Introduction}

Tau-associated neuropathology is a characteristic feature of a range of dementias (Iqbal et al., 2010; Morris et al., 2011).

\footnotetext{
Received June 4, 2015; revised 0ct. 14, 2015; accepted Nov. 16, 2015.

Author contributions: K.T.-A., M.W.J., A.D.R., and J.T.B. designed research; C.A.B., J.W., and J.N. performed research; C.A.B., J.W., J.N., K.T.-A., and J.T.B. analyzed data; C.A.B., J.W., M.W.J., A.D.R., and J.T.B. wrote the paper.

J.W. and C.A.B. were Medical Research Council funded CASE students co-funded by Pfizer. A.D.R. was a Royal Society Industry Fellow. M.W.J. was a Medical Research Council Non-Clinical Senior Research Fellow. J.T.B. was an Alzheimer's Research United Kingdom Senior Research Fellow. The mice were provided by Pfizer and Eli Lilly.

The authors declare no competing financial interests.

${ }^{*}$ C.A.B. and J.W. contributed equally to this study.

This article is freely available online through the J Neurosci Author Open Choice option.

Correspondence should be addressed to Dr. Jonathan T. Brown, Institute of Biomedical and Clinical Sciences, University of Exeter Medical School, Hatherly Laboratories, University of Exeter, Prince of Wales Road, Exeter EX4 4PS, UK. E-mail: J.T.Brown@exeter.ac.uk.
}

Studies in genetically engineered mice, which overexpress disease-relevant mutant forms of tau protein, have allowed the functional consequences of tauopathy to be probed and have typically established deficits in learning and memory, particularly in hippocampus-dependent tasks (McGowan et al., 2006). However, comparatively few studies have examined the neurophysiological cellular and network mechanisms underlying these deficits.

The rTg4510 mouse is a transgenic tau mutant overexpression

This is an Open Access article distributed under the terms of the Creative Commons Attribution License Creative Commons Attribution 4.0 International, which permits unrestricted use, distribution and reproduction in any medium provided that the original work is properly attributed. 
model, which develops hyperphosphorylated tau, neurofibrillary tangles, neurodegeneration, and associated cognitive impairments in an age-dependent manner (Ramsden et al., 2005; Santacruz et al., 2005; Spires et al., 2006). Work in this model has revealed tauopathy-associated morphological and electrophysiological changes in rTg4510 cortical neurons, including dendritic and synaptic atrophy, depolarization of the resting potential, and increased "sag" potentials (Rocher et al., 2010; Crimins et al., 2011, 2012). Furthermore, recent work has identified disturbances to hippocampal sharp wave-ripple oscillations (Witton et al., 2014) and spatial encoding in rTg4510 mice (Cheng and Ji, 2013), suggesting a level of hippocampal network dysfunction. Thus, it is apparent that tau-associated neuropathology induces changes in neuronal cellular and network physiology, likely leading to cognitive behavioral impairments in tasks dependent on these circuits.

In light of the evidence of disturbances in cellular and network properties in $\mathrm{rTg} 4510$ mice, we sought to determine whether we could correlate such changes within a behaviorally relevant network by combining cellular- and network-level electrophysiological analysis of hippocampal CA1 pyramidal neurons (CA1-PNs) with mathematical modeling approaches.

\section{Materials and Methods}

Ethical approval. All procedures were performed in accordance with the United Kingdom Animals (Scientific Procedures) Act 1986 and European Union Directive 2010/63/EU and were reviewed by the University of Bristol Ethical Review Group.

Experimental animals. rTg4510 mice and their wild-type (WT) littermates (Charles River) were used in this study. rTg4510 mice harbor cDNA encoding human four-repeat tau containing the P301L mutation under control of a tetracycline operon-responsive element (Santacruz et al., 2005). Mice were bred on a 129S6_FVB/N-F1 genetic background, weaned at 3 weeks of age, and housed according to gender and litter on a 12:12 h light:dark cycle with ad libitum access to food and water. Experiments were performed on 7- to 8-month-old male mice, housed singly for at least 2 weeks before experiments, which were performed during the circadian light phase.

In vitro electrophysiological recordings. A total of $300 \mu \mathrm{m}$ horizontal hippocampal slices were prepared in an ice-cold $\left(\sim 4^{\circ} \mathrm{C}\right)$ sucrose-based cutting solution (comprising the following in mм: 189 sucrose, 10 D-glucose, $26 \mathrm{NaHCO}_{3}, 3 \mathrm{KCl}, 5 \mathrm{MgSO}_{4}, 0.1 \mathrm{CaCl}_{2}, 1.25 \mathrm{NaH}_{2} \mathrm{PO}_{4}$ ) using a Leica VT1200 vibratome (Leica Microsystems), and whole-cell and extracellular recordings were made as described previously (Booth et al., 2014). For recording, slices were submerged in a chamber maintained at $32^{\circ} \mathrm{C}-33^{\circ} \mathrm{C}$ and continuously perfused $(\sim 2.5 \mathrm{ml} / \mathrm{min})$ with oxygenated aCSF containing the following (in $\mathrm{mm}$ ): $124 \mathrm{NaCl}, 3 \mathrm{KCl}, 24$ $\mathrm{NaHCO}_{3}, 2 \mathrm{CaCl}_{2}, 1.25 \mathrm{NaH}_{2} \mathrm{PO}_{4}, 1 \mathrm{MgSO}_{4}, 10$ D-glucose. Currentclamp recordings were made using an internal solution containing the following (in mM): $140 \mathrm{~K}$-gluconate, $10 \mathrm{NaCl}, 10 \mathrm{HEPES}, 0.2 \mathrm{EGTA}, 0.3$ Na-GTP, 4 Mg-ATP, pH 7.3, $295 \mathrm{mOsm} / \mathrm{L}$. A liquid junction potential of $15 \mathrm{mV}$ was corrected for arithmetically.

Square-wave current injections ( $500 \mathrm{~ms},-100$ or $300 \mathrm{pA}$ ) were used to measure subthreshold membrane properties or to evoke action potential (AP) firing. The impedance ( $Z$ ) amplitude profile (ZAP) method (Hu et al., 2002) was used to characterize the electrical resonance of CA1-PNs. The ZAP current consisted of a constant amplitude (range 30-100 pA) sinusoid with linearly increasing frequency (1-20 Hz over $30 \mathrm{~s})$.

Postsynaptic potentials were evoked by brief $(0.1 \mathrm{~ms})$ electrical stimulation of the Schaffer collateral (SC) and temporoammonic (TA) pathways. Extracellular field EPSPs (fEPSPs) were recorded in both stratum radiatum and stratum lacunosum moleculare of area CA1 (see Fig. $6 a$ ). For LTP experiments, baseline stimulation intensity was set to $40 \%-50 \%$ of the maximal response as determined from input-output curves from each slice for each pathway. Pathways were stimulated alternately at a baseline frequency of $0.067 \mathrm{~Hz}$. LTP was evoked using a theta-burst stimulation (TBS) paradigm (Larson et al., 1986) consisting of 5 bursts
(10 stimuli at $100 \mathrm{~Hz}$ ) delivered at $5 \mathrm{~Hz}$, repeated 4 times at an interval of $20 \mathrm{~s}$ (Nolan et al., 2004). Stimulation intensity and duration were constant throughout the entire experiment, including the theta-burst induction protocol.

In vitro electrophysiology data analysis. Analyses were performed using MATLAB (The MathWorks). To determine input resistance $\left(\mathrm{R}_{\mathrm{i}}\right)$ and membrane time constant $\left(\tau_{M}\right)$, a single exponential was fitted to the $10 \%-95 \%$ portion of the membrane charging curve in response to a 500 $\mathrm{ms}$ injection of $100 \mathrm{pA}$ hyperpolarizing current. Extrapolated $\mathrm{R}_{\mathrm{i}}$ was determined with Ohm's law from an infinite time extrapolation of this fit (Booth et al., 2014). The extrapolated $\mathrm{R}_{\mathrm{i}}$ reflects resting $\mathrm{R}_{\mathrm{i}}$ before the additional activation of $\mathrm{I}_{\mathrm{h}}$ that occurs upon hyperpolarization: \% sag = ((extrapolated voltage change - steady-state voltage change)/extrapolated voltage change) $\times 100$. AP threshold was measured as the voltage where the first derivative of the spike waveform exceeded $10 \mathrm{~V} / \mathrm{s}$. Impedance profiles were constructed by plotting frequency against the magnitude of the fast Fourier transform (FFT) of the ZAP voltage response, divided by the magnitude of the FFT of the ZAP current $(Z=\mathrm{V}(\mathrm{FFT}) /$ $\mathrm{I}(\mathrm{FFT})$ ). The ratio ( $\mathrm{Q}$ value) of the impedance at the resonance peak to the impedance at $1 \mathrm{~Hz}$ was used to quantify the strength of the resonance.

As SC fEPSPs were in most cases contaminated by population spikes following TBS, fEPSP slope was determined by fitting a straight line to the initial rising phase of the fEPSP. An identical time window ( $1 \mathrm{~ms}$ following the fiber volley, determined from baseline traces) was used for all slope measurements for each experiment. TA fEPSPs were small compared with SC fEPSPs, resulting in unreliable slope measurements in the TA pathway (mean coefficient of variation for baseline fEPSPs: TA slope, $\mathrm{WT}=0.24 \pm 0.05, \mathrm{rTg} 4510=0.34 \pm 0.09 ; \mathrm{SC}$ slope, $\mathrm{WT}=0.064 \pm$ $0.007, \mathrm{rTg} 4510=0.097 \pm 0.02$; TA amplitude, $\mathrm{WT}=0.073 \pm 0.009$, $\mathrm{rTg} 4510=0.046 \pm 0.009)$. Because population spikes were never observed in the TA pathway, fEPSP amplitude was measured as commonly reported in pathways with small synaptic response amplitudes (e.g., hippocampal mossy fiber pathway) (Mistry et al., 2011).

Modeling. To model the effect of the h-current on CA1 neuronal behavior, we extended our CA1 pyramidal model (Nowacki et al., 2011) to include an h-current. The h-current conductance was modeled using Hodgkin-Huxley formalism (Hodgkin and Huxley, 1952) as a noninactivating current with fast and slow activation components and is given by the equation, $I_{\mathrm{K}_{\mathrm{h}}}(V)=g_{\mathrm{K}_{\mathrm{h}}}\left(p m_{\mathrm{K}_{\mathrm{h}}}+(1-p) n_{\mathrm{K}_{\mathrm{h}}}\right)\left(V-E_{\mathrm{K}}\right)$, where $g_{\mathrm{K}_{\mathrm{h}}}=0.05$ is the maximal conductance of the current, $m_{\mathrm{K}_{\mathrm{h}}}$ is the fast activation component and $n_{\mathrm{K}_{\mathrm{h}}}$ is the slow activation component of the current, $p=0.85$ represents the proportional contribution of the fast component, $V$ is the membrane potential of the cell, and $E_{\mathrm{K}}$ is the reversal potential of the current, which was set to $E_{\mathrm{K}}=-90 \mathrm{mV}$. The gating variables are described by the ordinary differential equation as follows:

$$
\frac{d x}{d t}=\frac{x_{\infty}-x}{\tau_{x}}
$$

where $x_{\infty}$ are the steady-state activation functions and $\tau_{x}$ are time constants for each of the gating variables $x \in\left\{m_{\mathrm{Kh}_{\mathrm{h}}}, n_{\mathrm{K}_{\mathrm{h}}}\right\}$. The steadystate activation functions $m_{\mathrm{K}_{\mathrm{h}}}, n_{\mathrm{K}_{\mathrm{h}}}$ are defined using a single Boltzmann function, namely, $m_{\mathrm{Kh}_{\mathrm{h}}}(V)=\left(1+\exp \left(-\left(V-V_{\mathrm{Km}_{\mathrm{h}}}\right) / k_{\mathrm{Km}_{\mathrm{h}}}\right)\right)^{-1}$ and $n_{\mathrm{Kh}_{\mathrm{h}}}(V)=\left(1+\exp \left(-\left(V-V_{\mathrm{Kn}_{\mathrm{h}}}\right) / k_{\mathrm{Kn}_{\mathrm{h}}}\right)\right)^{-1}$, where $V_{\mathrm{Km}_{\mathrm{h}}}=V_{\mathrm{Kn}_{\mathrm{h}}}=$ $-102 \mathrm{mV}$ are the half-activations for the slow and fast components of the current, respectively; $k_{\mathrm{Km}_{\mathrm{h}}}=-13 \mathrm{mV}$ and $k_{\mathrm{Km}_{\mathrm{h}}}=-6 \mathrm{mV}$ are the slope of the functions. The current activation time constants are $\tau_{\mathrm{Km}_{\mathrm{h}}}=15 \mathrm{~ms}$ and $\tau_{\mathrm{Kn}_{\mathrm{h}}}=210 \mathrm{~ms}$.

In vivo electrophysiological recordings. Methods were as described previously (Witton et al., 2014). Briefly, mice were implanted with custom microdrives containing four independently movable tetrodes. Tetrodes were fabricated from four $12.5 \mu \mathrm{m}$ Formvar-insulated tungsten wires (California Fine Wire). Gold plating reduced the impedance to $200-300 \mathrm{k} \Omega$.

Mice were anesthetized using isoflurane (4\% induction, $1 \%-2 \%$ maintenance) and fixed in a stereotaxic frame. Seven watchmakers' screws were inserted into the skull to anchor the microdrive. A craniotomy was made over right parietal cortex, and tetrodes were implanted into the brain at stereotaxic coordinates (relative to bregma): anteropos- 
terior, -2.0 to $2.2 \mathrm{~mm}$; mediolateral, $1.5-2.0 \mathrm{~mm}$. Tetrodes were implanted to a depth of $0.5-0.7 \mathrm{~mm}$ from the brain surface, which was sealed off using a $70 \%$ paraffin wax $/ 30 \%$ mineral oil mixture. Silver ground and reference wires were connected to anchor screws overlying the cerebellum. Gentamycin-impregnated bone cement was used to anchor the microdrive to the skull.

After 1 week of postoperative recovery, tetrodes were advanced 30-60 $\mu \mathrm{m}$ per day until neurophysiological signatures characteristic of the CA1 pyramidal cell layer could be identified (i.e., ripple oscillations, theta modulation, complex spiking cells). Signals were recorded by connecting the microdrive to a unity-gain headstage tethered to an analog highdensity recording system (Neuralynx). One tetrode was targeted to white matter dorsal to the hippocampus as a local reference.

Tetrodes recorded local field potentials (LFPs) and, in several animals, single units. LFPs were filtered between 1 and $475 \mathrm{~Hz}$ and sampled at 2 $\mathrm{kHz}$. LFPs were acquired from all three tetrodes, with one of these signals selected for analyses. Efforts were made to ensure consistent neuroanatomical placement of the LFP electrode across animals, based on post hoc histology. Units were threshold triggered at $50 \mu \mathrm{V}$, filtered between 600 and $6000 \mathrm{~Hz}$, and digitized at $30 \mathrm{kHz}$. Units were referenced to the local reference, whereas LFPs were referenced to the cerebellar ground screw. This was to prevent parietal or volume conducted hippocampal network activity detected on the local reference from biasing the hippocampal LFP. The animal's position was tracked at $25 \mathrm{~Hz}$ using two light-emitting diodes on the headstage and an overhead video camera.

For experiments, mice were placed on a familiar linear track $(80 \times 5$ $\mathrm{cm}$, with $10 \times 10 \mathrm{~cm}$ turning zones at either end) and were required to run from end-to-end for appetitive rewards $(25 \mu \mathrm{l} 10 \%$ condensed milk in water). Mice were not food restricted but were habituated to the reward. A black or white spatial cue card was placed on the wall of the recording room at either end of the track. Recording sessions lasted for 15 min and were repeated across two consecutive days. Tetrodes were adjusted at the end of the first recording session to optimize their placement for the following day.

At the end of experiments, mice received an overdose of sodium pentobarbital (Euthetal), and electrolytic lesions were made at the tetrode tips (30 $\mu \mathrm{A}$ anodal current, $10 \mathrm{~s}$ ). Mice were transcardially perfused with $1 \times$ PBS followed by $4 \% \mathrm{v} / \mathrm{v}$ formaldehyde in $1 \times$ PBS. Tetrodes were retracted, and the brain was removed from the skull. Brains were postfixed in $4 \%$ formaldehyde for a minimum of $24 \mathrm{~h}$ and cryoprotected in $30 \% \mathrm{w} / \mathrm{w}$ sucrose in $1 \times$ PBS for $\sim 48 \mathrm{~h}$. Brains were cut into $50 \mu \mathrm{m}$ coronal sections, mounted onto slides, and stained using thionin. Final recording positions were confirmed using bright-field microscopy.

In vivo electrophysiology data analysis. Analyses were performed in MATLAB. Animal position and running speed were estimated from the video tracking $(25 \mathrm{~Hz})$ of the headstage light-emitting diodes. $X$ and $Y$ pixel coordinates were converted to centimeters by scaling to the dimensions of the camera field of view. Tracking positions were then binned (by linear interpolation) into $0.5 \mathrm{~s}$ epochs and the speed determined from the distance traveled in each bin. As hippocampal network activity is modulated by animal running speed (Chen et al., 2011), LFP analyses were performed on epochs in which the running speed was between 10 and 20 $\mathrm{cm} / \mathrm{s}$. Signals recorded during these epochs were concatenated and detrended to generate a speed filtered LFP. Multitaper Fourier power analysis (Mitra and Pesaran, 1999) was performed using the Chronux toolbox (Bokil et al., 2010). Phase-amplitude coupling (PAC) was assessed using a PAC detection toolbox (Onslow et al., 2011). Spectral power and the extent of PAC across different frequency bands were estimated from the integral of the Fourier periodogram and PAC comodulogram, respectively.

Single units were isolated by clustering the spikes using KlustaKwik 1.7 (http://klusta-team.github.io/klustakwik/) followed by verification and refinement in MClust 3.5 (http://redishlab.neuroscience.umn.edu/ MClust/Mclust.html). Cluster quality inclusion criteria were as follows: isolation distance $>15.0$; L-ratio $<0.35$ (Schmitzer-Torbert et al., 2005). Putative units were rejected if the mean firing rate was $<0.1 \mathrm{~Hz}$, or had $>0.3 \%$ of spikes within a $2 \mathrm{~ms}$ refractory period. CA1-PNs were classified using standard waveform (peak-to-trough width $>260 \mu \mathrm{s}$ ) and mean firing rate $(<5 \mathrm{~Hz})$ analyses (Ranck, 1973). The complex spike index was the percentage of consecutive spikes with an interspike interval $<15 \mathrm{~ms}$ where the peak amplitude of the second spike was smaller than the first (McHugh et al., 1996). The theta modulation index was calculated from the Fourier transform of the $\pm 500 \mathrm{~ms}$ spike-train autocorrelation, as described previously (Langston et al., 2010; Wills et al., 2010). Spiketrains that contained $<100$ spikes during theta-state epochs (running speed $>5 \mathrm{~cm} / \mathrm{s}$ ) were excluded from theta modulation analysis.

Firing rate maps were constructed by dividing the track length into 4 $\mathrm{cm}$ bins and dividing the number of spikes fired in each bin by the occupancy time in each bin. As place cells routinely exhibit directionality in linear environments (McNaughton et al., 1983), left-to-right and right-to-left running trajectories were analyzed separately and the datasets pooled. Activity on a given trajectory was analyzed if the cell's mean firing rate was $>0.1 \mathrm{~Hz}$ on that trajectory. To exclude spikes fired during stationary behavior, laps that took $>16 \mathrm{~s}$ to complete (mean running speed $<5 \mathrm{~cm} / \mathrm{s}$ ) were excluded. Spatial information was calculated using Skaggs' formula (Skaggs et al., 1996) as follows:

$$
\text { Spatial information }=\sum_{i} P_{i} \frac{R_{i}}{R} \log _{2} \frac{R_{i}}{R}
$$

where $i$ is the bin number, $P_{i}$ is probability of occupancy for bin $i, R_{i}$ is the mean firing rate for bin $i$, and $\mathrm{R}$ is the overall mean firing rate. Spatial information measures the extent to which a cell's firing predicts the animal's location, expressed in bits/spike. Spatial information was calculated using adaptively smoothed rate maps to maximize the trade-off between sampling error and blurring error, as previously described (Langston et al., 2010; Wills et al., 2010; Chen et al., 2013). To calculate the firing rate in bin $i$, a window centered on $i$ was expanded until:

$$
r \geq \frac{\alpha}{n \sqrt{ } s}
$$

where $r$ is the radius (or half-width) of the widow, $\alpha$ is a constant (1000), and $n$ and $s$ are the number of occupancy samples and spikes in the window, respectively. To account for the possibility of cells having multiple discontinuous firing fields on the track, a cell's firing field was defined as the percentage of the track length (contiguous and noncontiguous bins) where the firing rate exceeded $10 \%$ of the peak firing rate (Nakazawa et al., 2003). Lap-by-lap rate-stability was defined as the mean Pearson correlation coefficient calculated between the firing rate maps of all possible pairs of individual laps, as previously described (Cheng and Ji, 2013).

Statistical analyses. Statistical analyses were performed using SPSS (IBM) or MATLAB (The MathWorks). Datasets were tested for normality, and parametric or nonparametric tests were used as appropriate with an $\alpha$ level of 0.05 . Where appropriate, two-way ANOVA was used to compare datasets across multiple factors. Where the sphericity assumption was violated, a Huynh-Feld correction was applied to adjust the degrees of freedom. Post hoc comparisons were made using a Bonferonni correction for multiple comparisons. Data are mean \pm SEM unless otherwise stated. Medians are presented for non-normal datasets, with interquartile range in square brackets.

\section{Results}

\section{CA1 network activity in rTg4510 mice}

Impaired performance in the Morris water maze (Morris et al., 1982) confirmed that mice in our rTg4510 cohort exhibited impaired hippocampal function at the $7-8$ month age point used for electrophysiological analyses (Fig. 1a). To examine neurophysiological correlates of hippocampal dysfunction in awake, behaving rTg4510 mice, CA1 LFPs were recorded in 6 WT and 7 rTg4510 mice as they traversed a linear track, baited at either end with appetitive rewards. Recording electrode positions were confirmed by post hoc histology (Fig. $1 b$ ). During periods when mice traversed the track at a velocity of $10-20 \mathrm{~cm} / \mathrm{s}(\mathrm{WT}=13.2 \pm 0.3$ $\mathrm{cm} / \mathrm{s}, \mathrm{rTg} 4510=13.2 \pm 0.4 \mathrm{~cm} / \mathrm{s}, t_{(11)}=0.16, p=0.87$, unpaired $t$ test), WT LFPs displayed a clear peak in the theta frequency 
a

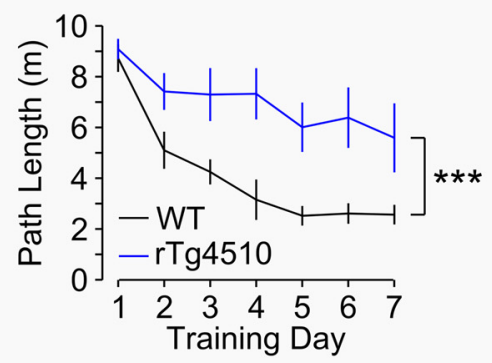

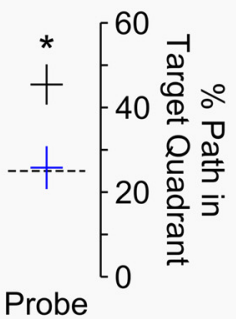

d

C

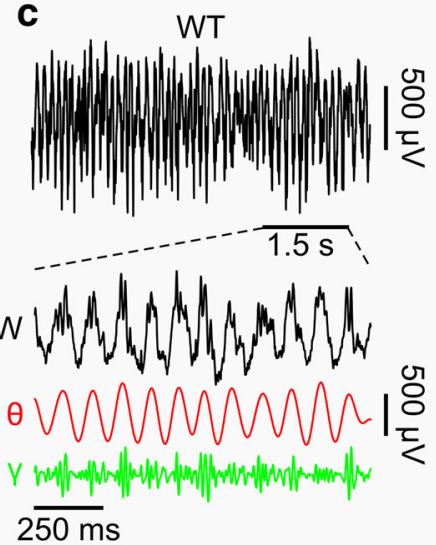

$2 \overline{50 \mathrm{~ms}}$ b

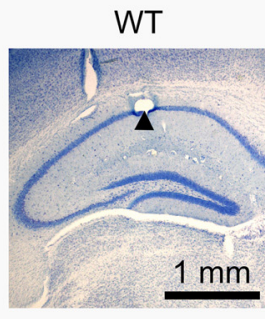

e
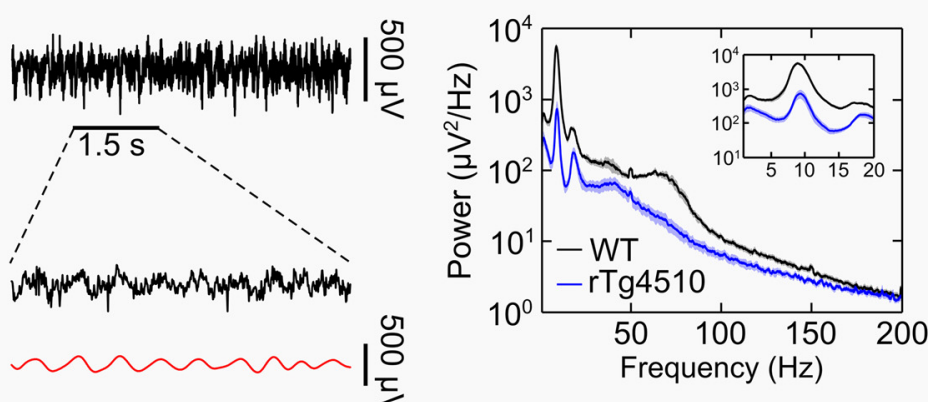

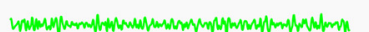

\section{g}
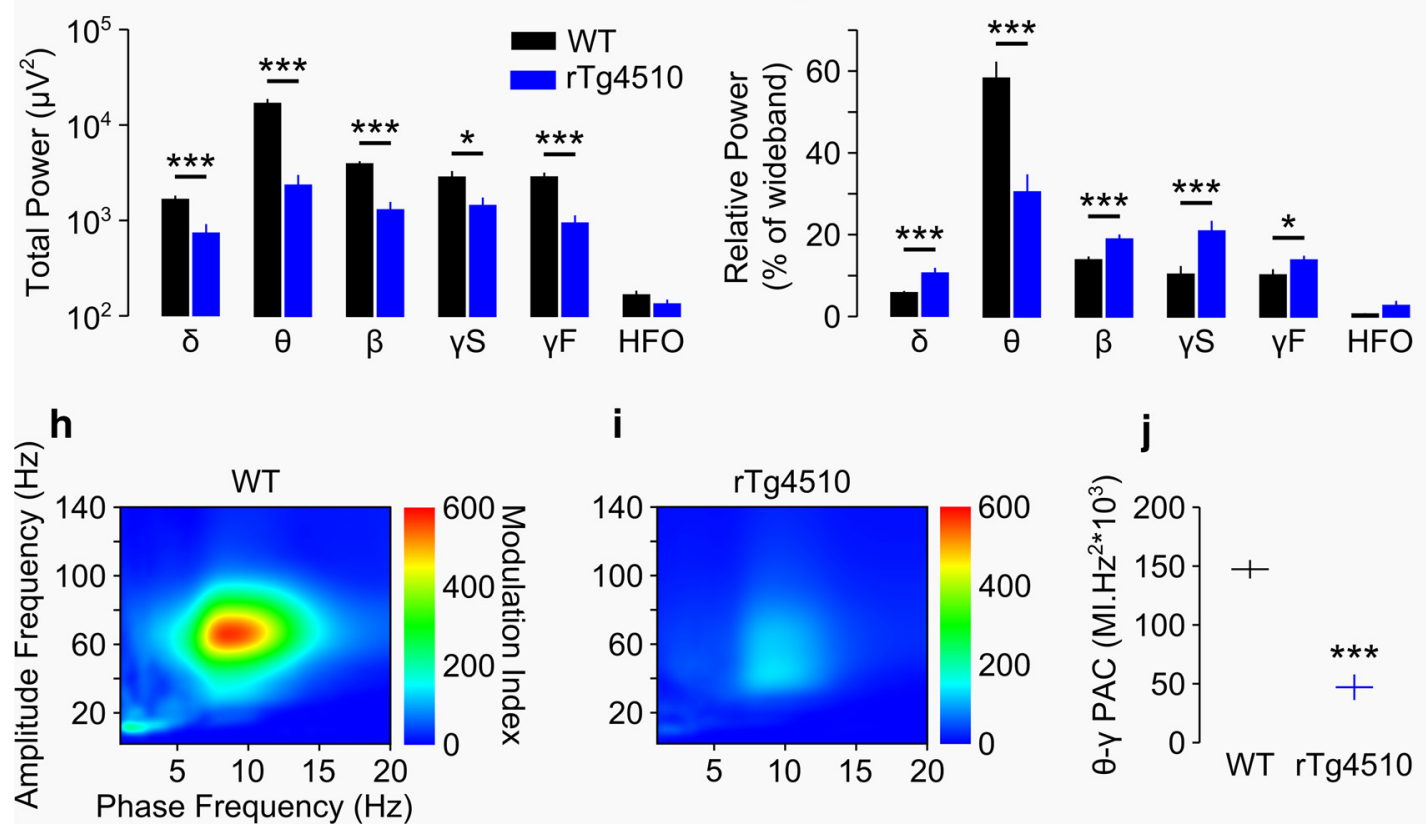

Figure 1. Impaired spatial memory is associated with aberrant CA1 network oscillations and theta-gamma phase-amplitude coupling in 7-to 8-month-old rTg4510 mice. $\boldsymbol{a}$, Hidden platform and probe task performance in the Morris water maze in WT $(n=10)$ and $\mathrm{rTg} 4510(n=10)$ mice. The maze consisted of a 1-m-diameter circular pool filled with opacified water and was surrounded by overt visual cues. A 9-cm-diameter escape platform was concealed $\sim 1 \mathrm{~cm}$ beneath the water in one of the four maze quadrants. The length of swim path required to locate the escape platform was measured within a 60 s time limit and averaged across four consecutive trails ( 30 s intertrial interval). The probe trial was performed on day 8 . The escape platform was removed, and the length of swim path spent searching the target maze quadrant was measured within a 30 s time limit. Dashed line plots the chance performance level (25\% path length inside target maze quadrant). $\boldsymbol{b}$, Photomicrographs of Nissl-stained coronal brain sections illustrating recording positions (arrows) in the CA1-PN layer in a representative WT and rTg4510 mouse. $\boldsymbol{c}$, $\boldsymbol{d}$, The $5 \mathrm{~s}$ traces of raw LFP recorded in the CA1-PN layer of a representative WT (c) and rTg4510 (d) mouse. Expanded traces of wideband (W, 1-200 Hz), theta $(\theta$, red, $4-12 \mathrm{~Hz})$, and gamma $(\gamma$, green, $25-120 \mathrm{~Hz}) \mathrm{LFPs}$ are plotted below. In the WT traces (c), peaks in gamma amplitude coincide with peaks in the theta cycle, an example of theta-gamma PAC. $e$, Periodogram illustrating the wideband power spectral density (PSD) of CA1 LFPs in WT and rTg4510 mice. Inset, Plot of the 1-20 Hz PSD. f, Total PSD (integral of periodogram) for discrete frequency bands of CA1 network oscillations in WT and rTg4510 mice: delta ( $\delta$; $1-4 \mathrm{~Hz})$; theta $(\theta)$; beta $(\beta ; 12-25 \mathrm{~Hz})$; slow gamma $(\gamma S ; 25-50 \mathrm{~Hz})$; fast gamma ( $\gamma \mathrm{F} ; 50-120 \mathrm{~Hz})$; high-frequency oscillations (HF0; $120-200 \mathrm{~Hz})$. g, Relative PSD (\% wideband power) for discrete frequency bands of CA1 network oscillations in WT and rTg4510 mice. $\boldsymbol{h}, \boldsymbol{i}$, Population-averaged comodulograms illustrating theta-gamma PAC in WT CA1 LFPs (h) and strong attenuation of theta-gamma PAC in rTg4510 CA1 LFPs (i). $\boldsymbol{j}$, Quantification of theta-gamma PAC. $\boldsymbol{e}-\boldsymbol{g}$, $\boldsymbol{h}$, Data are mean \pm SEM from $n=6$ WT and $n=7$ rTg4510 mice. ${ }^{*} p<0.05$. ${ }^{* * *} p<0.005$. 
a

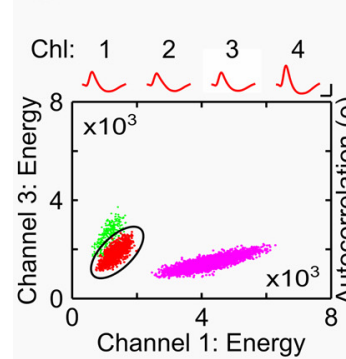

c

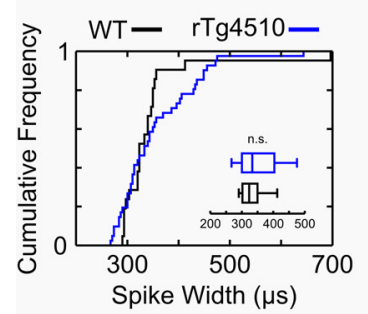

WT

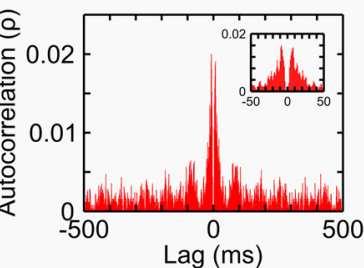

d

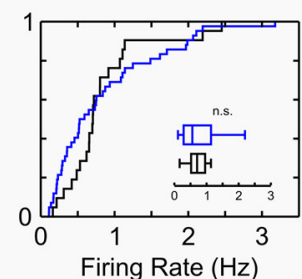

b

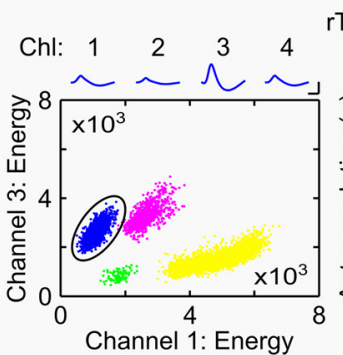

e

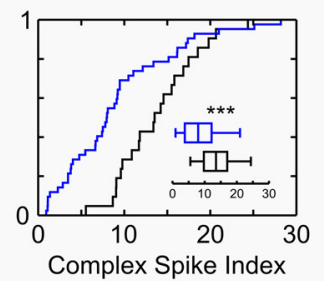

rTg4510

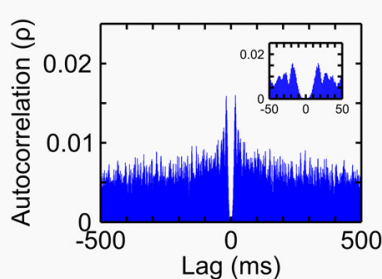

f

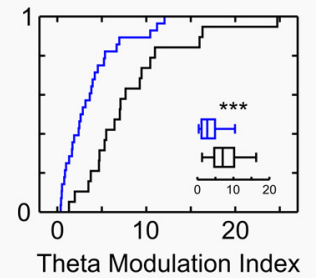

g
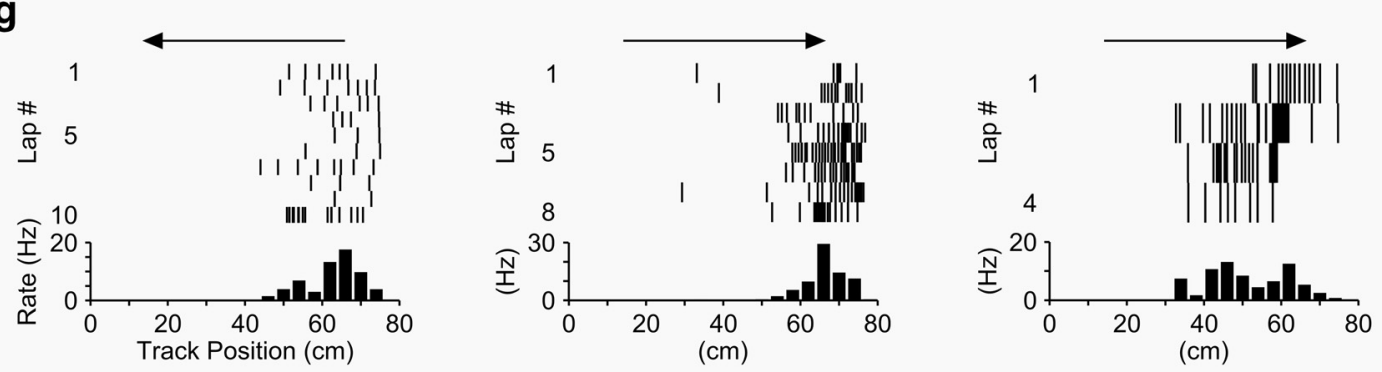

h
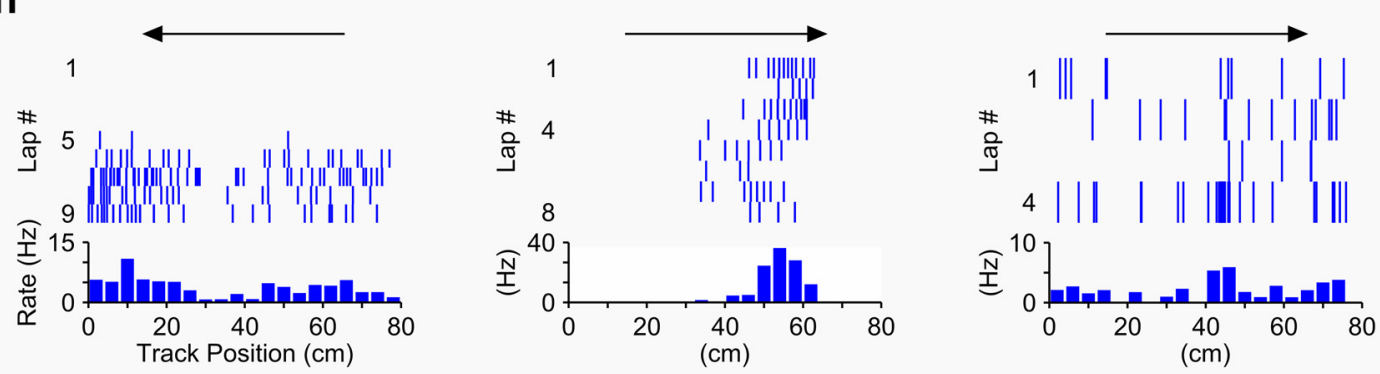

i

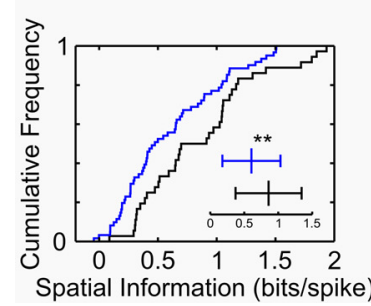

j

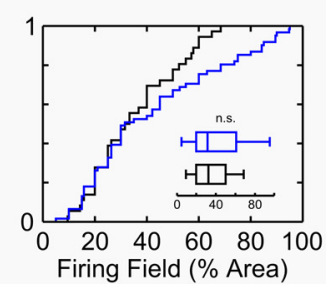

k

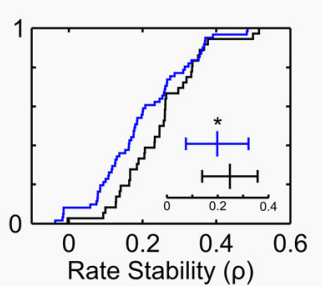

Figure 2. Altered firing properties of CA1 pyramidal neurons in behaving 7- to 8-month-old rTg4510 mice. a, Scatter plot (left) represents the waveform energies of extracellular APs recorded on two channels of a representative WT tetrode. Colors highlight clusters of APs discharged by individual neurons. Nonclustered APs have been omitted for clarity. Mean AP waveforms on each tetrode channel are displayed for the red unit cluster (circled). Calibration: $100 \mu \mathrm{V}, 250 \mu \mathrm{s}$. Right, Spike-train autocorrelation for the red unit cluster. Note the prominent peak in the $0-50 \mathrm{~ms}$ autocorrelation (inset), illustrating the tendency for the cell to burst fire, and the $\sim 100 \mathrm{~ms}$ (theta) periodicity. $\boldsymbol{b}$, As for $\boldsymbol{a}$ for a representative rTg 4510 tetrode. Note the lack of obvious $\sim 100 \mathrm{~ms}$ periodicity in the blue unit cluster autocorrelation and the reduced prominence of a peak at short latency lags. Calibration: $100 \mu V, 250 \mu$ s. $c-f$, Cumulative frequency plots illustrating the distributions of WT $(n=21)$ and rTg4510 $(n=42)$ CA1-PN spike widths (c), firing rates (d), complex spike indices $(\boldsymbol{e})$, and theta modulation indices $(\boldsymbol{f})$. $\boldsymbol{g}$, Lap-by-lap raster plots for the circled WT cell in $\boldsymbol{a}$ and two other representative cells recorded in two different WT mice. Track position is plotted on the abscissa. Arrows indicate the direction of track traversal. Each tick indicates the firing position of an AP. The averaged firing rate map is plotted below. $\boldsymbol{h}$, As for $\boldsymbol{g}$ for the circled rTg4510 cell in $\boldsymbol{b}$ and two other representative cells recorded in two different rTg4510 mice. $\boldsymbol{i}-\boldsymbol{k}$, Cumulative frequency plots illustrating the distributions of WT ( $n=36$ trajectories) and rTg4510 ( $n=61$ trajectories) CA1-PN spatial information indices $(i)$, firing field sizes $(j)$, and lap-by-lap rate stabilities $(\boldsymbol{k}) . \mathbf{c}-\boldsymbol{f}, \boldsymbol{i}-\boldsymbol{k}$, Inset, Box plots represent the median, first and third quartiles, and $99 \%$ confidence limits. Line plots (normally distributed data) represent the mean \pm SD. ns, Not significant at $p>$ 0.05. ${ }^{*} p<0.05 .{ }^{* *} p<0.01 .{ }^{* *} p<0.005$. 
band ( $4-12 \mathrm{~Hz})$, with less prominent peaks in the $\delta(1-4 \mathrm{~Hz}), \beta$ $(12-25 \mathrm{~Hz})$, and slow and fast gamma $(25-50 \mathrm{~Hz}$ and $50-120 \mathrm{~Hz}$, respectively) frequency bands (Fig. 1c,e). Equivalent recordings made from $\mathrm{rTg} 4510$ mice revealed an $\sim 75 \%$ deficit in wideband LFP power in $\operatorname{rTg} 4510$ mice $\left(\mathrm{WT}=28,300 \pm 1400 \mu \mathrm{V}^{2}\right.$, rTg4510 $=7000 \pm 1400 \mu \mathrm{V}^{2}, F_{(1,11)}=143.2, p=3.4 \times 10^{-18}$, two-way ANOVA; Fig. 1d,e). A factorial ANOVA also detected a significant interaction between genotype and frequency band $\left(F_{(1.2,13.6)}=57.5, p=1.0 \times 10^{-6}\right)$, suggesting LFP power to be more depressed in $\mathrm{rTg} 4510$ mice at certain frequencies. Post hoc comparisons showed that power was significantly decreased for all frequencies up to and including the fast gamma band (Fig. $1 f$ ) and that the greatest proportional decrease occurred in the theta band, such that in WT mice the theta component comprised $58.2 \pm 3.8 \%$ of the wideband LFP, whereas in $\mathrm{rTg} 4510$ mice the theta component only comprised $30.4 \pm 4.1 \%$ of the total signal. As a result, the proportion of the signal contributed by all the other frequency bands to the wideband LFP was significantly increased in $\mathrm{rTg} 4510$ mice (Fig. $1 \mathrm{~g}$ ). Contrary to a previous report in rTg4510 mice (Cheng and Ji, 2013), peak theta oscillation frequency was not affected by genotype (WT $=9.0 \pm 0.1 \mathrm{~Hz}$, rTg4510 $=9.2 \pm 0.1 \mathrm{~Hz}, t_{(11)}=0.99, p=0.34$, unpaired $t$ test). This discrepancy is potentially the product of controlling for animal running speed in spectral analyses in the present study, as running speed modulates the power (Chen et al., 2011) and frequency (Slawinska and Kasicki, 1998) of hippocampal theta oscillations.

The phase of hippocampal theta oscillations is dynamically coupled to the amplitude of concurrent gamma oscillations (Bragin et al., 1995). This PAC is thought to support hippocampus-dependent cognitive processes, including certain forms of context-specific (Tort et al., 2009) and spatial memory (Tort et al., 2008). From the same data, we calculated the modulation index (MI) (Canolty et al., 2006) across a range of frequencies to generate a comodulogram. In WT mice, the phase of the theta oscillation was strongly coupled to the amplitude of gamma oscillations, particularly in the fast gamma band (peak modulating frequency: $8.5 \pm$ $0.1 \mathrm{~Hz}$, peak modulated frequency: $66 \pm 1.0 \mathrm{~Hz}$; Fig. $1 c, h)$. As we could not clearly discriminate PAC between theta-slow gamma and theta-fast gamma oscillations, the extent of coupling was estimated between theta and slow-to-fast gamma frequencies (25-120 Hz), such that theta-gamma coupling in WT mice was $147,000 \pm 8000 \mathrm{MI} \cdot \mathrm{Hz}^{2}$. When this analysis was performed on rTg4510 CA1 LFPs, we found a substantial deficit in thetagamma coupling $\left(47,000 \pm 11,000 \mathrm{MI} . \mathrm{Hz}^{2}, t_{(11)}=7.25, p=\right.$ $1.6 \times 10^{-5}$, unpaired $t$ test; Fig. $\left.1 d, i, j\right)$.

\section{CA1 pyramidal neuron activity in $\mathrm{rTg} 4510$ mice in vivo}

Network oscillations facilitate the coordination of spiking in neuronal circuits (Buzsáki and Draguhn, 2004). To explore whether the changes in hippocampal network oscillations in $\mathrm{rTg} 4510$ mice were mirrored by changes in cellular activity, we examined the spiking of isolated CA1-PNs recorded while mice traversed the linear track.

We isolated 21 and 42 CA1-PN units (see Materials and Methods) from 5 WT and 3 rTg4510 mice, respectively (Fig. 2a,b). Spike-widths $(\mathrm{WT}=323 \mu \mathrm{s}[296,347], \mathrm{rTg} 4510=333 \mu \mathrm{s}[300$, 403], $Z=0.87, p=0.39$, rank-sum test) and firing rates (WT $=$ $0.71 \mathrm{~Hz}[0.52,0.96], \mathrm{rTg} 4510=0.56 \mathrm{~Hz}[0.29,1.14], Z=0.66$, $p=0.51$, rank-sum test) were not significantly affected by genotype (Fig. 2c,d). Quantification of the level of burst firing by CA1PNs (complex spike index; see Materials and Methods), however, revealed that rTg4510 CA1-PNs had a reduced propensity to fire
Table 1. Intrinsic membrane properties of CA1-PNs from 7- to 8-month-old rTg4510 and WT mice ${ }^{a}$

\begin{tabular}{lccl}
\hline & WT $(n=39)$ & $\operatorname{rTg} 4510(n=27)$ & $p$ \\
\hline Subthreshold membrane properties & & & \\
RMP $(\mathrm{mV})$ & $-79.5 \pm 0.4$ & $-78.1 \pm 0.6$ & 0.060 \\
$\mathrm{R}_{\mathrm{i}}(\mathrm{m} \Omega)$ & $134.5 \pm 5.1$ & $147.3 \pm 9.8$ & 0.21 \\
$\tau_{\mathrm{M}}(\mathrm{ms})$ & $18.6 \pm 0.8$ & $16.3 \pm 0.6$ & $0.035^{*}$ \\
$\%$ sag & $24.9 \pm 1.2$ & $29.7 \pm 1.6$ & $0.016^{*}$ \\
Negative peak $(\mathrm{mV})$ & $-12.6 \pm 0.3$ & $-13.5 \pm 0.9$ & 0.32 \\
Rebound $(\mathrm{mV})$ & $2.3 \pm 0.1$ & $2.8 \pm 0.2$ & $0.014^{*}$ \\
Action potential properties & & & \\
Peak (mV) & $30.8 \pm 0.9$ & $31.7 \pm 1.4$ & 0.58 \\
Width (ms) & $0.79 \pm 0.02$ & $0.81 \pm 0.01$ & 0.32 \\
Threshold (mV) & $-57.4 \pm 0.7$ & $-59.3 \pm 0.8$ & 0.061 \\
Maximum rate of rise $(\mathrm{V} / \mathrm{s})$ & $471 \pm 12$ & $520 \pm 21$ & $0.040^{*}$ \\
\hline
\end{tabular}

${ }^{a}$ RMP, Resting membrane potential.

*Significant.

high-frequency bursts $(\mathrm{WT}=13.5[9.7,17.0], \mathrm{rTg} 4510=8.0$ [3.8, 12.1], $Z=3.26, p=1.1 \times 10^{-3}$, rank-sum test; Fig. $2 e$ ). Theta-frequency modulation of CA1-PN spiking (Buzsáki, 2002) (theta modulation index; see Materials and Methods) was also significantly decreased in $\mathrm{rTg} 4510$ mice $(\mathrm{WT}=7.0[4.7,10.2]$, $\operatorname{rTg} 4510=2.7[1.2,4.9], Z=3.37, p=7.5 \times 10^{-4}$, rank-sum test; Fig. $2 f$ ), suggesting that the changes in oscillatory drive in the hippocampus in rTg4510 mice disturb the structure of neuronal firing.

In a given environment, subsets of hippocampal pyramidal neurons exhibit firing tuned to specific locations (O'Keefe and Dostrovsky, 1971) and are thus posited to encode environmental space (Moser et al., 2008). Recent work has demonstrated the spatial specificity of CA1 "place cell" activity to be reduced in 7to 9-month-old rTg4510 mice as a result of these cells having unstable firing locations (Cheng and Ji, 2013). Based on the observation of aberrant CA1-PN spiking in rTg4510 mice, we determined whether similar aberrant spatial coding was present in our sample of rTg4510 CA1-PNs. Lap-by-lap raster plots and averaged firing rate maps were constructed for WT and rTg4510 CA1-PNs for each running trajectory on the linear track. Most WT CA1-PNs active on each trajectory (mean firing rate $>0.1$ $\mathrm{Hz}$ ) exhibited spatially modulated firing characteristic of place cells (Fig. 2g). Although some rTg4510 CA1-PNs displayed place cell activity (Fig. $2 h$, middle), across the population the location specificity of rTg4510, CA1-PN firing (spatial information; see Materials and Methods) was significantly decreased (WT = $0.86 \pm 0.08, \mathrm{rTg} 4510=0.61 \pm 0.05, t_{(95)}=2.67, p=8.9 \times 10^{-3}$, unpaired $t$ test; Fig. $2 i$ ). Total firing field sizes ( $\%$ of track length) were comparable between the two genotypes (WT $=32.4 \%$ $[20.0,50.0], \mathrm{rTg} 4510=31.6 \%[20.0,60.8], Z=0.99, p=0.32$, rank-sum test; Fig. 2j), although there was greater variability in the rTg4510 CA1-PN population (quartile coefficient of variation, $\mathrm{WT}=0.43, \mathrm{rTg} 4510=0.50)$. As has been observed (Cheng and Ji, 2013), however, analysis of the lap-to-lap spatial firing stability, defined as the average spatial correlation between the firing rate maps of all laps, revealed that rTg4510 CA1-PNs had significantly lower rate stability $(\mathrm{WT}=0.25 \pm 0.02, \mathrm{rTg} 4510=$ $0.20 \pm 0.02, t_{(95)}=2.00, p=0.048$, unpaired $t$ test; Fig. $2 k$ ), likely accounting for the reduced spatial information scores of these cells. These findings link the previous observation of impoverished spatial coding by CA1-PNs in rTg4510 mice (Cheng and Ji, 2013) to impaired network oscillations at the network/LFP level. 

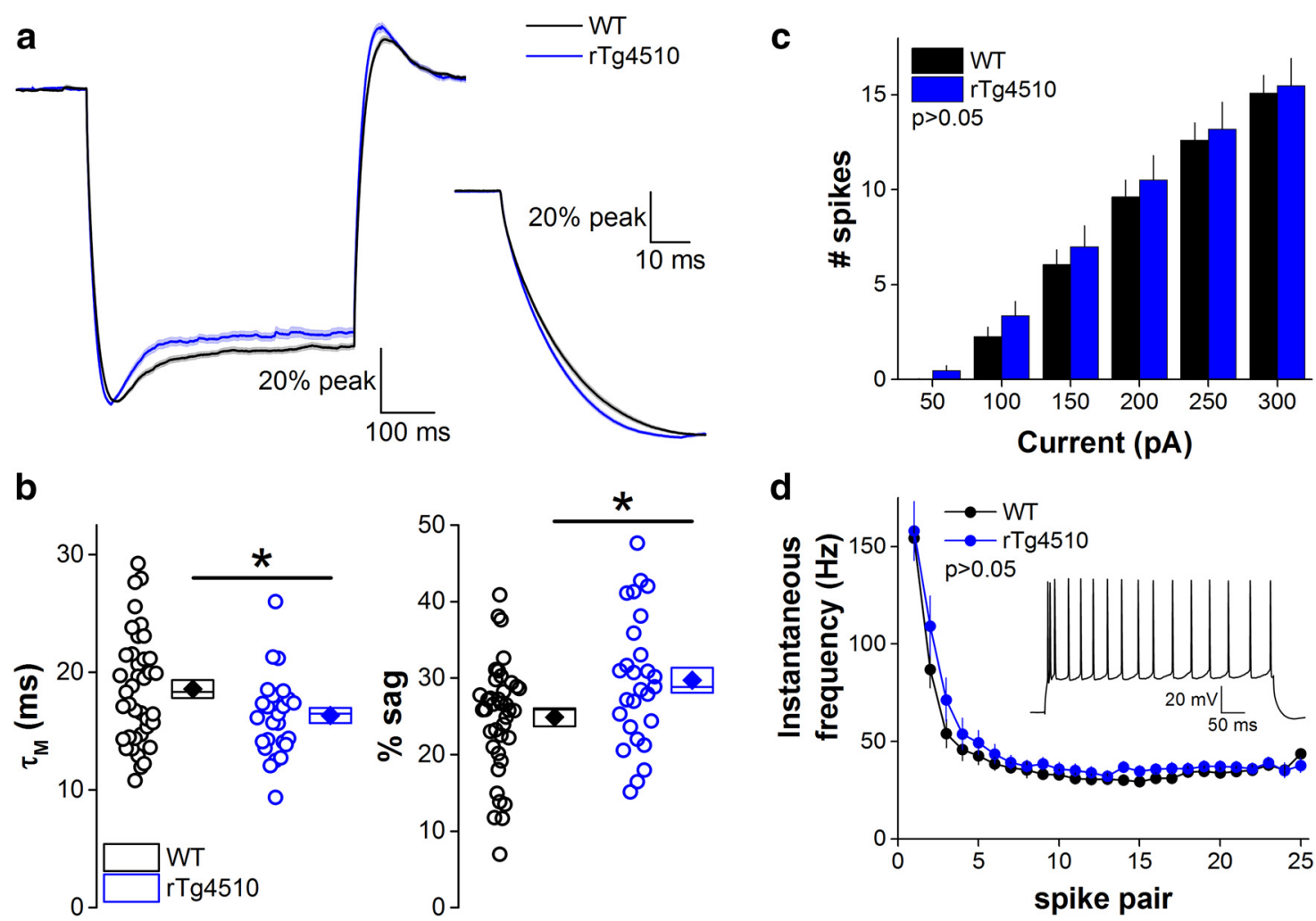

Figure 3. Faster membrane time constant and increased $\mathrm{I}_{\mathrm{h}}$-mediated sag potential in rTg4510 CA1 pyramidal neurons. $\boldsymbol{a}$, Left, Full-scale mean peak normalized traces (WT, black; $\mathrm{rTg} 4510$, blue) in response to $500 \mathrm{~ms},-100 \mathrm{pA}$ current injection. Right, Initial response on a larger time scale reveals the difference in $\tau_{\mathrm{M}}$ more clearly. Shaded areas represent the SEM. $\boldsymbol{b}$, Scatter plots represent membrane time constant $\left(\tau_{\mathrm{M}}\right.$ ) and percentage sag from all recorded neurons (open symbols). Mean (filled symbols), SEM (box), and median (central line) are shown on the right. c, The number of action potentials elicited by $500 \mathrm{~ms}$ depolarizing current injection steps was not different between WT and rTg4510 CA1-PNs. $\boldsymbol{d}$, Instantaneous frequency between consecutive spike pairs in response to $500 \mathrm{~ms}, 300 \mathrm{pA}$ depolarizing current injection steps reveals no significant differences in firing patterns between genotypes. Inset, Representative example trace from a rTg4510 CA1-PN showing the initial high-frequency burst of action potentials followed by accommodation to $\sim 35 \mathrm{~Hz} . n=39 \mathrm{WT}$ and $n=27 \mathrm{rTg} 4510$ CA1-PNs. ${ }^{*} p<0.05$.

Intrinsic membrane properties of CA1 pyramidal neurons The intrinsic membrane properties of individual neurons have a profound influence on the way they respond to ongoing network activity (Traub et al., 2004; Harvey et al., 2009; Lee et al., 2012). Electrophysiological data obtained in vivo from behaving mice suggested alterations in the cellular neurophysiology of CA1-PNs in rTg4510 mice. Current-clamp recordings were therefore made from $39 \mathrm{WT}$ and $27 \mathrm{rTg} 4510 \mathrm{CA1}-\mathrm{PNs}$ in hippocampal slices prepared from 7 - to 8-month-old mice to ascertain a range of subthreshold and suprathreshold intrinsic membrane properties (Table 1). While most of these parameters were unaffected by genotype, we observed a significantly faster membrane time constant $\left(\tau_{\mathrm{M}} ; \mathrm{WT}=18.6 \pm 0.8 \mathrm{~ms}, \mathrm{rTg} 4510=16.3 \pm 0.6 \mathrm{~ms}\right.$, $t_{(64)}=2.15, p=0.035$, unpaired $t$ test $)$ and increased h-currentmediated $\left(\mathrm{I}_{\mathrm{h}}\right)$ sag potential $(\mathrm{WT}=24.9 \pm 1.2 \%, \mathrm{rTg} 4510=$ $29.7 \pm 1.6 \%, t_{(64)}=2.47, p=0.016$, unpaired $t$ test) in $\mathrm{rTg} 4510$ CA1-PNs (Table 1; Fig. $3 a, b$ ). There was also an increase in the rebound potential in $\mathrm{rTg} 4510 \mathrm{CA1}-\mathrm{PNs}$, which likely reflects the enhanced sag potential because the rebound potential in CA1PNs corresponds to the slow deactivation of $\mathrm{I}_{\mathrm{h}}$ following membrane repolarization. AP peak, threshold, and width at $-15 \mathrm{mV}$ were unaltered by genotype, although there was a small but significant increase in the maximum rate of rise in $\mathrm{rTg} 4510 \mathrm{CA1}$ PNs (Table 1), which likely reflects the significantly shorter $\tau_{\mathrm{M}}$. Importantly, there was no detectable difference in AP firing patterns $\left(F_{(1,57)}=2.07, p=0.16\right.$, two-way ANOVA on first 5 spike pairs $)$ or the number of APs $\left(F_{(1,64)}=0.41, p=0.52\right.$, two-way ANOVA) elicited by depolarizing current injections (Fig. $3 c, d$ ), suggesting that the changes in subthreshold membrane properties do not substantially affect the core excitability of rTg4510 CA1-PNs.

Alterations in membrane kinetics and sag potentials may affect the way in which neurons respond to phasic oscillatory inputs. In this regard, CA1-PNs resonate within the theta frequency band, such that they are tuned to respond to synaptic inputs in this frequency range (Hutcheon and Yarom, 2000; Hu et al., 2002). In CA1-PNs, theta frequency membrane resonance arises from the combination of a relatively slow $\tau_{\mathrm{M}}$ and the presence of slowly activating and noninactivating voltage-gated conductances, such as $\mathrm{I}_{\mathrm{h}}$ and $\mathrm{I}_{\mathrm{m}}$ (Hu et al., 2002; Nolan et al., 2004; Peters et al., 2005). We therefore explored whether the changes in $\tau_{M}$ and sag in $\mathrm{rTg} 4510$ CA1-PNs affected their resonance properties. The voltage response to a sinusoidal ZAP current (see Materials and Methods) produced a maximal response when the current waveform was oscillating in the theta frequency band in both genotypes at a range of different membrane potentials (Fig. 4a). To quantify this, we derived impedance profiles for $24 \mathrm{WT}$ and 16 rTg4510 CA1-PNs (Fig. 4b) and found that the peak resonance frequency in $\mathrm{rTg} 4510 \mathrm{CA1}$-PNs was significantly higher than WT CA1-PNs $\left(F_{(1,38)}=5.72, p=0.022\right.$, two-way ANOVA; Fig. $\left.4 c\right)$, although still within the theta band. We also observed a significant increase in the strength of resonance $\left(\mathrm{Q} ; F_{(1,38)}=12.72, p=\right.$ $1.0 \times 10^{-3}$, two-way ANOVA) in rTg4510 CA1-PNs compared with WT CA1-PNs (Fig. 4d).

To explore the effects of alterations in $\tau_{\mathrm{M}}$ and sag on the resonance properties of CA1-PNs, we used a Hodgkin-Huxley type 
a

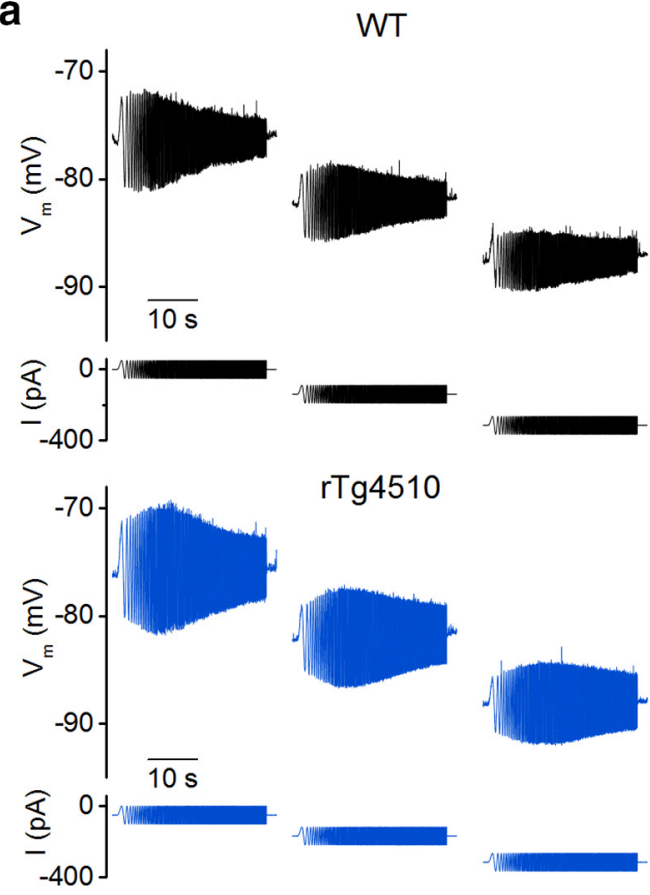

C

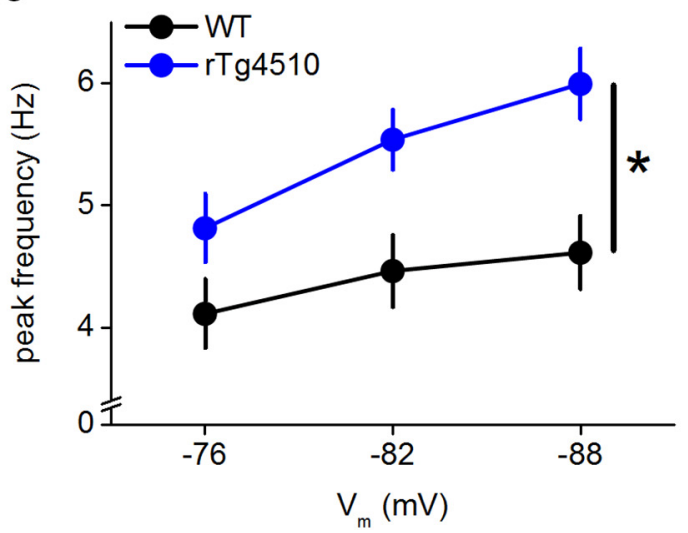

b
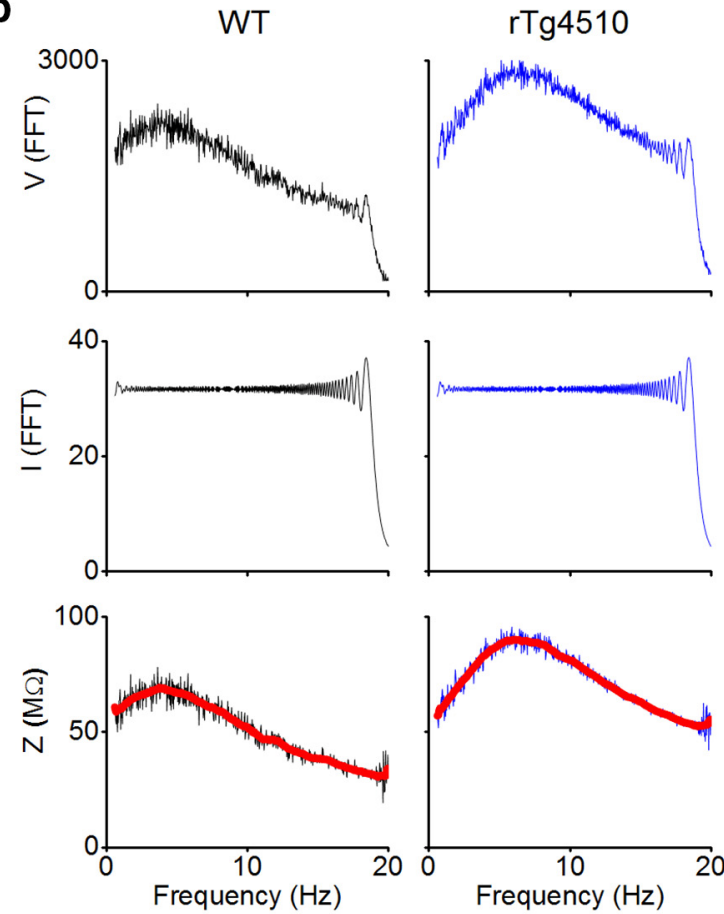

d

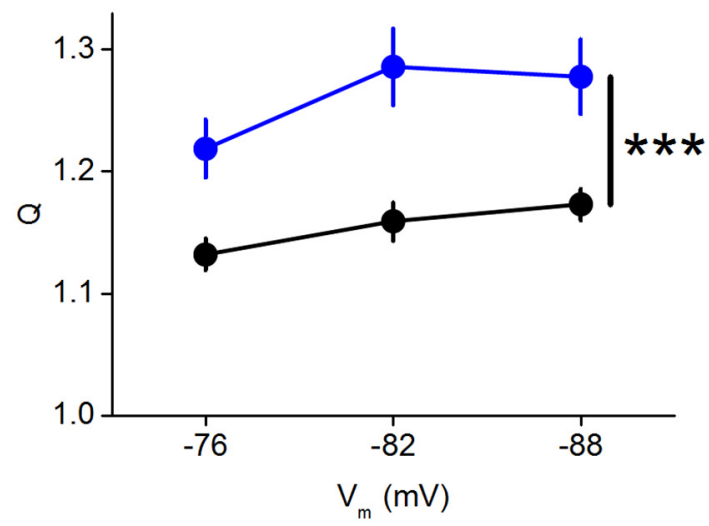

Figure 4. Resonance properties are altered in $\mathrm{rTg} 4510$ CA1 pyramidal neurons. $\boldsymbol{a}$, Representative traces from WT (top) and rTg4510 (bottom) CA1-PNs showing the ZAP current protocol and corresponding voltage responses at $-76,-82$, and $-88 \mathrm{mV}$. $\boldsymbol{b}$, Impedance ( $Z$ ) profiles (bottom) are calculated by dividing the FFT of the voltage response (top) by the FFT of the current injection (middle). Red line indicates the smoothed Z profile (bottom). $\boldsymbol{c}, \boldsymbol{d}$, Peak resonance frequency $(\boldsymbol{c})$ and strength of resonance $(\mathbf{Q} ; \boldsymbol{d})$ were significantly higher in rTg4510 CA1-PNs compared with WT. Data are mean \pm SEM from $n=24$ WT and $n=16$ rTg4510 CA1-PNs. ${ }^{*} p<0.05$. ${ }^{* *} p<0.005$.

single-compartment model neuron. Increasing capacitance $\left(\mathrm{C}_{M}\right)$ without altering $\mathrm{R}_{\mathrm{i}}$ increased $\tau_{\mathrm{M}}$ (Fig. $5 a, b$ ) as expected, since $\mathrm{C}_{\mathrm{M}}$ $\times \mathrm{R}_{\mathrm{i}}=\tau_{\mathrm{M}}$. Notably, we found that keeping $\mathrm{R}_{\mathrm{i}}$ constant and decreasing $C_{M}$ (and thereby $\tau_{M}$ ) of the model neuron, without altering relative amounts of $\mathrm{I}_{\mathrm{h}}$, resulted in an increase in sag potential (Fig. 5a,b) similar to that determined experimentally in rTg4510 CA1-PNs. In addition, decreasing $\mathrm{C}_{\mathrm{M}}$ shifted peak resonance frequency to higher frequencies and increased strength of resonance, as observed in rTg4510 CA1-PNs (Fig. $5 c, d$ ). Finally, altering the membrane capacitance was also sufficient to alter the maximum rate of rise of the AP in the model, in a manner consistent with our experimental results (Fig. $5 b$ ). Based on the results from this model, a reduction in membrane capacitance of $\sim 30 \%$ appeared to be sufficient to produce changes equivalent to the mean changes in the neurophysiological parameters measured experimentally. Specifically, when $\mathrm{C}_{M}$ was reduced by $30 \%$, sag ratio increased from $26.4 \%$ to $29.4 \%$ in the model, similar to the difference between WT and rTg4510 CA1-PNs observed experimentally (Table 1). Similarly, membrane time constant was $2.8 \mathrm{~ms}$ faster in the model when $\mathrm{C}_{\mathrm{M}}$ was reduced by $30 \%$, whereas the difference in mean $\tau_{\mathrm{M}}$ between WT and rTg4510 was $\sim 2.3$ ms. A $30 \%$ reduction in $C_{M}$ was also sufficient to produce a similar change in membrane resonance properties; thus, at -86 $\mathrm{mV}$, peak resonance frequency increased by $2.9 \mathrm{~Hz}$, whereas the experimentally observed mean difference between WT and rTg4510 resonance frequency was $\sim 1.4 \mathrm{~Hz}$. These data suggest that a reduction in $\mathrm{C}_{\mathrm{M}}$ of $\sim 30 \%$ is sufficient to produce all the other changes in intrinsic membrane properties observed in rTg4510 CA1-PNs (for illustration of these data, see Fig. 5, reference lines).

\section{Hippocampal synaptic transmission and plasticity}

As well as intrinsic membrane properties, synaptic transmission in hippocampal circuits plays a crucial role in determining the 
output patterns of individual component neurons (Brun et al., 2008; Nakashiba et al., 2009). For example, deficits in CA3CA1 Schaffer collateral (SC) synaptic transmission results in reduced burst firing of CA1-PNs (Nakashiba et al., 2009). Given that CA1-PNs are less likely to fire in bursts in rTg4510 mice in vivo (Fig. 2) and yet are intrinsically capable of generating similar burst frequencies at a cellular level (Fig. 3d), we reasoned that glutamatergic synaptic transmission in this pathway might also be disturbed. To test this hypothesis, we made extracellular recordings of field EPSPs in response to stimulation of the SC input in hippocampal slices. The mean input-output relationship recorded in rTg4510 slices was significantly attenuated compared with WT slices (WT $n=12, \operatorname{rTg} 4510 n=12, F_{(1,22)}=9.20, p=$ $6.1 \times 10^{-3}$, repeated-measures ANOVA; Fig. $6 b$, left). We also examined LTP induced by TBS of the SC pathway and found no significant difference in the ability of rTg4510 synapses to support LTP compared with WT slices (WT $n=$ 10, $\operatorname{rTg} 4510 n=11, t_{(19)}=1.25, p=$ 0.23 , unpaired $t$ test; Fig. $6 c$, top). This finding is in contrast to the deficit in SC LTP previously reported in $\mathrm{rTg} 4510$ mice (Hoover et al., 2010); however, the different age of mice (4.5 months and thus different expression of tau pathology) and TBS protocol used may account for this discrepancy; and importantly, Hoover et al. (2010) did observe SC LTP in rTg4510 mice, albeit to a lesser degree than in WT mice.

In addition to the SC pathway, axons from layer II entorhinal cortex innervate the distal dendrites of CA1-PNs via the TA pathway. This input has a strong modulatory role on CA1-PN activity in vivo (Brun et al., 2008). We therefore also constructed input-output relationships for the TA input into CA1 and found no significant difference between genotypes $(\mathrm{WT} n=12, \operatorname{rTg} 4510 n=$ $8, F_{(1,18)}=1.29, p=0.27$, repeated-measures ANOVA; Fig. $6 b$, right), suggesting that entorhinal glutamatergic inputs onto the distal dendrites of CA1-PNs function within normal parameters. However, while WT slices supported significant levels of LTP in the TA pathway $1 \mathrm{~h}$ after TBS $\left(123 \pm 5 \%\right.$ baseline, $n=11, t_{(10)}=$ 4.97, $p=5.6 \times 10^{-4}$, one-sample $t$ test), identical stimulation patterns in $\mathrm{rTg} 4510$ slices did not result in significant LTP $(96 \pm$ $6 \%$ baseline, $n=8, t_{(7)}=0.69, p=0.51$, one-sample $t$ test; WT vs $\mathrm{rTg} 4510, t_{(17)}=3.70, p=1.8 \times 10^{-3}$, unpaired $t$ test; Figure $6 c$, bottom).

LTP of the TA synaptic input onto CA1-PNs is dependent on the precise regulation of GABAergic, and in particular $G_{A B A}$ receptor-mediated, synaptic transmission (Remondes and Schuman, 2003). Therefore, we reasoned that GABAergic synaptic transmission in the TA pathway may be disturbed. Whole-cell current-clamp recordings from CA1-PNs revealed that IPSPs evoked with a sin-
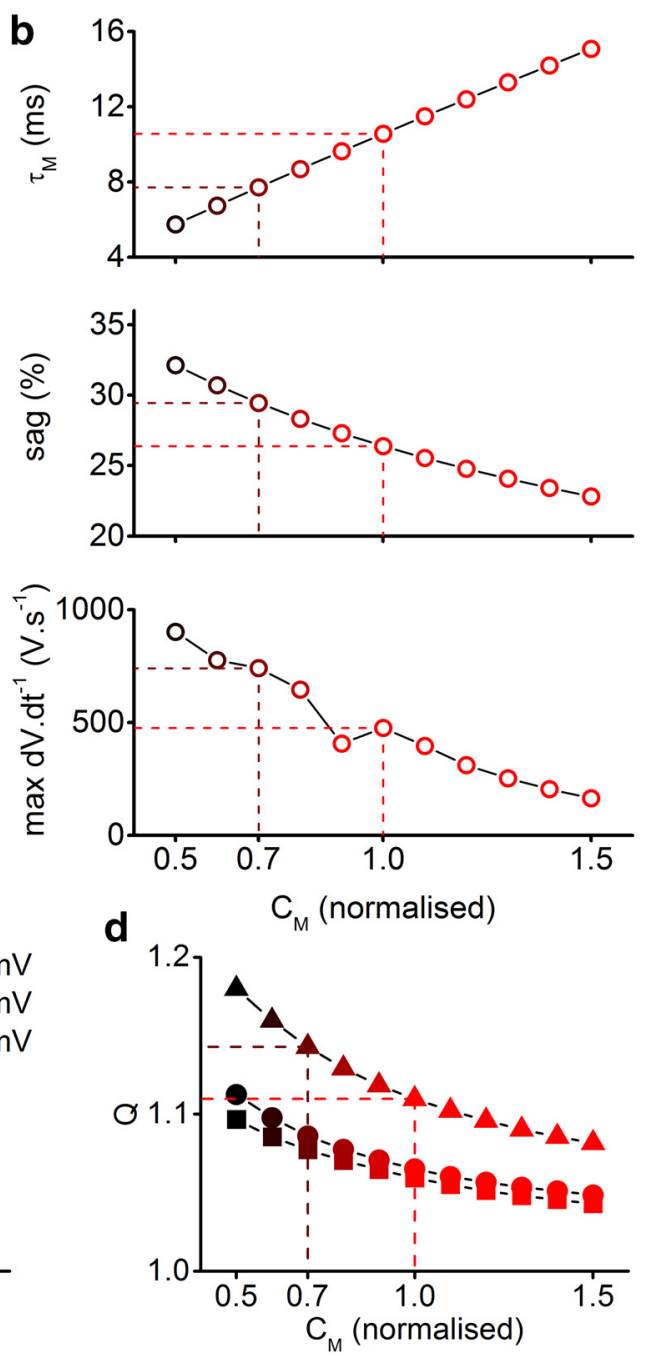

Figure 5. Changes in membrane capacitance are sufficient to produce experimentally observed changes in intrinsic membrane properties. $\boldsymbol{a}$, Simulated voltage response to a current stimulus in a Hodgkin-Huxley style single compartment model of a CA1 pyramidal neuron. When the simulated membrane capacitance $\left(C_{M}\right)$ was systematically increased (lighter red traces) or decreased (dife voltage response were observed, which were particularly evident during the initial charging were decreased and increased, respectively, in response to a reduction in $C_{M}$. Furthermore, the maximal rate of rise of simulated (Table 1). $\boldsymbol{c}, \boldsymbol{d}$, Peak membrane resonance frequency $(\boldsymbol{c})$ and resonance quotient $(\mathbf{Q} ; \boldsymbol{d})$ are also increased in response to decreased membrane capacitance (and vice versa). As observed experimentally, these effects are voltage-dependent.

gle stimulus in the TA pathway were biphasic; the slower component was sensitive to a $\mathrm{GABA}_{\mathrm{B}}$ receptor antagonist (CGP55845, 1 $\mu \mathrm{M})$, and the faster component was blocked by a $\mathrm{GABA}_{\mathrm{A}}$ receptor antagonist (gabazine, $2 \mu \mathrm{M}$; Fig. $7 a$ ). Trains of 6 stimuli delivered at a range of frequencies $(5,10,20,50$, and $100 \mathrm{~Hz})$ evoked summated IPSPs, which were sensitive to CGP55845 and gabazine (Fig. $7 b$ ). The amplitudes of the summated TA IPSPs were larger in rTg4510 CA1-PNs compared with WT counterparts $\left(\mathrm{WT} n=19, \operatorname{rTg} 4510 n=10, F_{(1,27)}=3.94, p=0.057\right.$, two-way ANOVA; Fig. $7 b, c)$, suggesting that an enhancement of GABAergic signaling may underlie the deficit in TA LTP in rTg4510 slices. In the presence of antagonists of $\mathrm{GABA}_{\mathrm{A}}$ and $\mathrm{GABA}_{\mathrm{B}}$ receptors, the magnitude of LTP $1 \mathrm{~h}$ after TBS in WT slices was comparable with that observed with inhibition intact $\left(127 \pm 7 \%\right.$ baseline, $n=12, t_{(21)}=0.41, p=0.69$; unpaired $t$ test). Strikingly, GABA receptor antagonists rescued the deficit in TA LTP in rTg4510 slices (115 $\pm 6 \%$ baseline, 
a

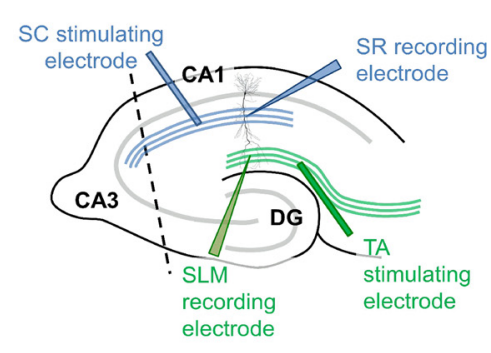

C

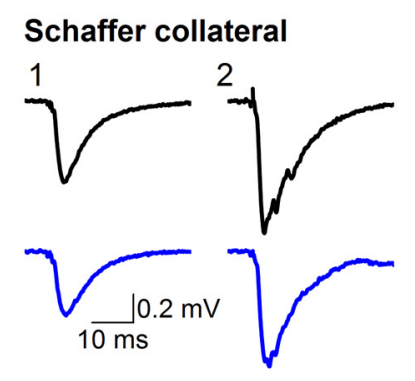

Temporoammonic

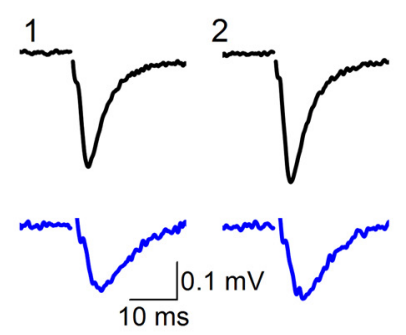

b

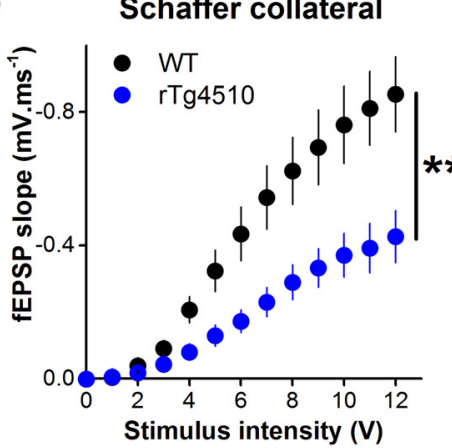

Temporoammonic

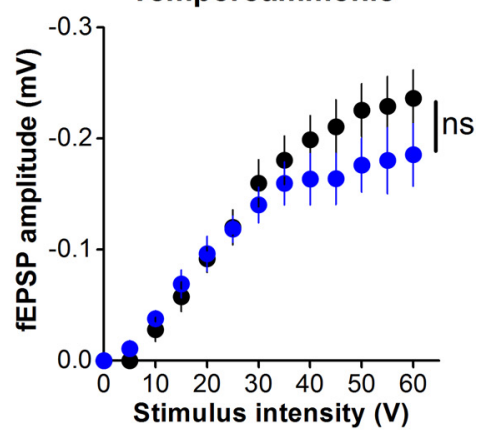

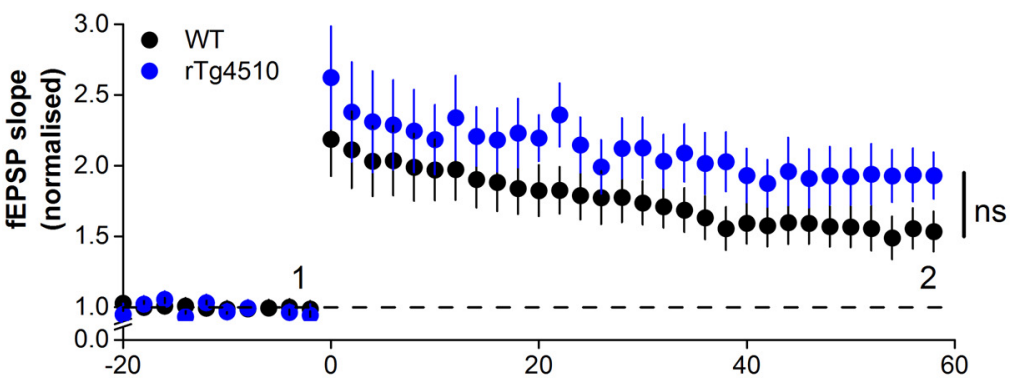

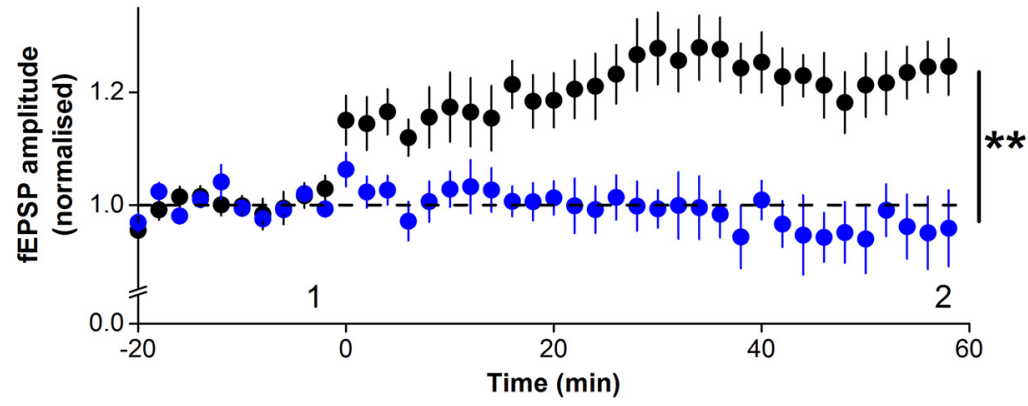

Figure 6. Basal synaptic transmission and LTP in the Schaffer collateral and temporoammonic pathways. $\boldsymbol{a}$, Schematic representation of the hippocampus showing approximate positions of stimulating and recording electrodes. SR, Stratum radiatum; SLM, stratum lacunosum moleculare; DG, dentate gyrus. $\boldsymbol{b}$, Basal synaptic transmission is reduced in the SC pathway (left) but unaltered in the TA pathway (right) in slices from rTg4510 mice compared with WT. c, TBS-induced LTP is unaffected by genotype in the SC pathway (top) but significantly reduced in the TA pathway (bottom) in rTg4510 slices compared with WT. Left, Representative traces from baseline (1) and 60 min after TBS (2) from WT (black) and rTg4510 (blue) slices. Stimulus artifacts were removed for clarity. Right, Time course of normalized fEPSP slope (SC) or amplitude (TA) (see Materials and Methods) following TBS. SC, $n=10$ WT and $n=11 \mathrm{rTg} 4510$ slices; TA, $n=11 \mathrm{WT}$ and $n=8 \mathrm{rTg} 4510$ slices. ns, Not significant at $p>0.05 .{ }^{* *} p<0.01$.

$n=13, t_{(12)}=2.36, p=0.036$; one-sample $t$ test) to a similar level as that observed in WT slices (WT vs $\mathrm{rTg} 4510, t_{(23)}=$ $1.24, p=0.23$, unpaired $t$ test; Fig. $7 d)$.

\section{Discussion}

In this study, we describe interrelated neurophysiological mechanisms, which culminate in impaired hippocampal information processing in tauopathy. These include the following: (1) changes to the intrinsic properties of CA1-PNs; (2) impaired synaptic innervation of surviving CA1-PNs, particularly via the Schaffer collateral pathway; and (3) impaired entorhinal-hippocampal communication and plasticity mediated by dysregulation of temporoammonic GABAergic transmission.

\section{Altered intrinsic membrane properties}

Intrinsic electrical properties of individual neurons, along with the weightings of synaptic connections, play a fundamental role in shaping the dynamics of neuronal networks (Buzsáki et al., 2012). Theta resonance of hippocampal CA1-PNs is thought to play an important role in tuning these cells to respond to theta frequency inputs (Hutcheon and Yarom, 2000; Hu et al., 2002). Slowly activating, noninactivating, voltage-gated conductances, such as $\mathrm{I}_{\mathrm{h}}$ and $\mathrm{I}_{\mathrm{m}}$, contribute to the resonance properties of CA1$\mathrm{PNs}$ in a voltage-dependent fashion, such that, at hyperpolarized potentials, $\mathrm{I}_{\mathrm{h}}$-mediated resonance is dominant, whereas at more depolarized potentials, $\mathrm{I}_{\mathrm{m}}$ plays a greater role (Hu et al., 2002). There were striking changes to the resonance profile in rTg4510 CA1-PNs, specifically increased peak resonance frequency and strength of resonance (Fig. 4). In rTg4510 CA1-PNs, we observed a significant increase in $\mathrm{I}_{\mathrm{h}}$-mediated sag potential (Fig. 3), similar to that reported in studies of $\mathrm{rTg} 4510$ layer 3 frontal cortical neurons (Rocher et al., 2010; Crimins et al., 2012). These studies also revealed dendritic and synaptic atrophy in rTg4510 cortical neurons (Rocher et al., 2010; Crimins et al., 2012). Such morphological changes would alter membrane capacitance, which, as our modeling suggests, could contribute to changes in sag and resonance (Fig. 5). The magnitude of the changes in intrinsic membrane properties are relatively small; however, as the mathematical model demonstrates, an overall reduction in membrane 


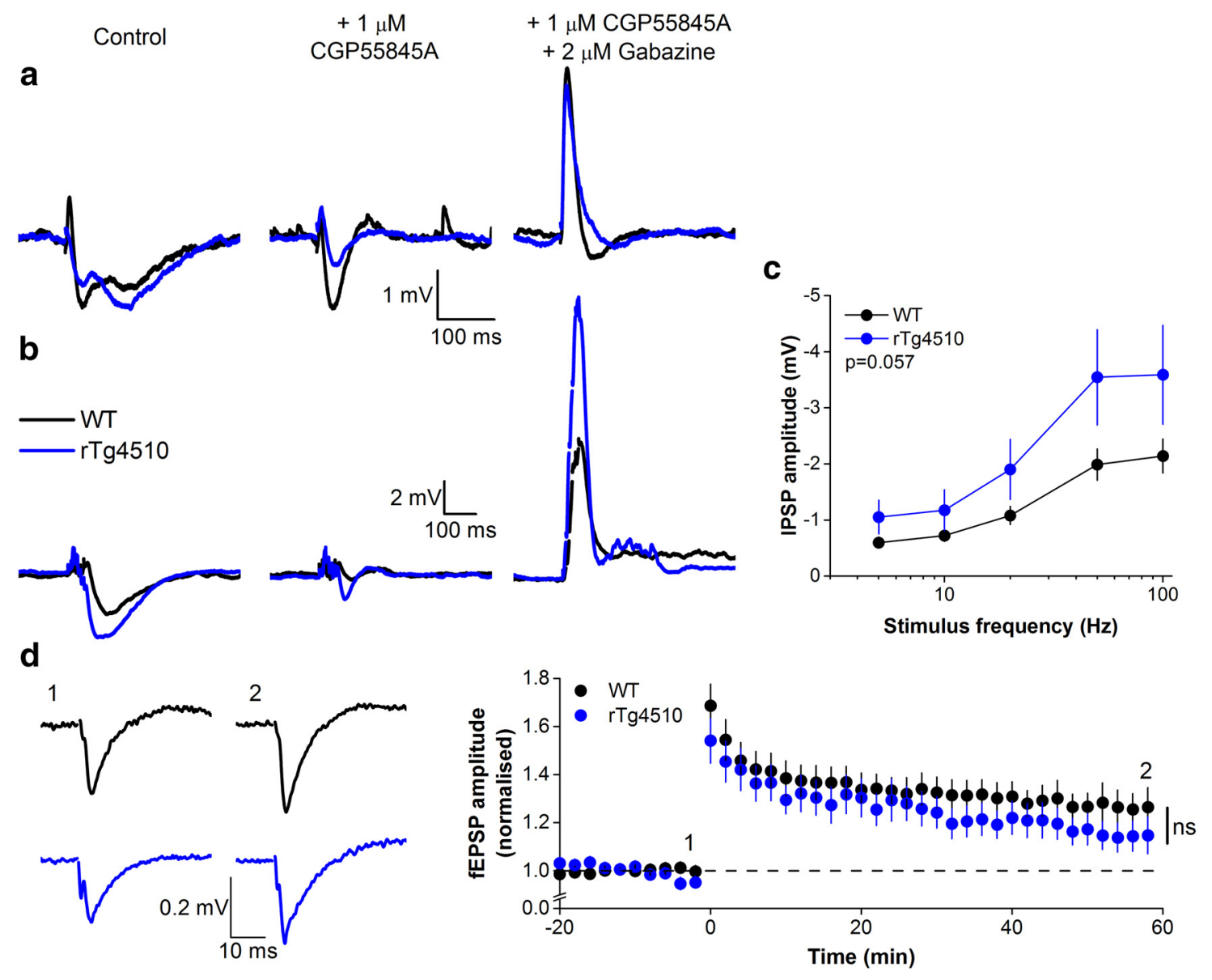

Figure 7. Enhanced temporoammonic IPSP in rTg4510 CA1 pyramidal neurons and blockade of GABA receptors rescue deficit in temporoammonic LTP. $\boldsymbol{a}, \boldsymbol{b}$, Representative current-clamp recordings from WT (black) and rTg4510 (blue) CA1-PNs in response to a single stimulus (a) and 6 stimuli delivered at $100 \mathrm{~Hz}(\boldsymbol{b})$ to the temporoammonic pathway in control conditions, in the presence of the $G A B A_{B}$ receptor antagonist CGP55845A, and in the presence of CGP55845A and the GABA $A_{A}$ antagonist Gabazine. Note the biphasic IPSP in response to a single stimulus $(\boldsymbol{a})$ in control conditions, the slow component of which is abolished in the presence of CGP55845A. c, Pooled IPSP amplitudes against stimulation frequency. $n=19$ WT and $n=10 \mathrm{rTg} 4510$ CA1-PNs. $\boldsymbol{d}$, In the presence of GABA antagonists ( $2 \mu \mathrm{m}$ Gabazine and $1 \mu \mathrm{M}$ CGP55845A), TBS-induced LTP in the temporoammonic pathway is not different between WT and rTg4510 slices. Left, Representative traces from baseline (1) and 60 min after TBS (2) from WT (black) and rTg4510 (blue) slices. Right, Time course of normalized fEPSP amplitude following TBS in the presence of GABA antagonists. $n=12$ WT and $n=12$ rTg4510 slices. ns, Not significant at $p>0.05$. In all traces, stimulus artifacts were removed for clarity.

capacitance of $\sim 30 \%$ would be sufficient to produce these neurophysiological effects. Such a change in membrane capacitance likely results from a reduction in dendritic complexity, as has been elegantly described for frontal cortical neurons (Rocher et al., 2010; Crimins et al., 2012). Although it is not trivial to directly translate electrophysiologically determined capacitance measures to morphological measurements of dendritic structure (not least because of the cable-filtering properties of the neuronal processes), a reduction of $30 \%$ membrane surface area appears to be feasible based on the results from these published data.

Altered membrane resonance of CA1-PNs may have a number of functional consequences. Changes to the input impedance within the theta frequency band will alter the cellular responsiveness to theta frequency inputs within the local network. When driven at frequencies in the theta range, rTg4510 CA1-PNs require $\sim 20 \%-25 \%$ less current to produce a given voltage change (Fig. 4b), and thus may be hyperexcitable. In rTg4510 mice, the altered CA1-PN theta frequency resonance evident in vitro was accompanied by a decrease in LFP theta power and striking deficits in theta modulation of single-unit activity in vivo. The changes to intrinsic properties may therefore be a compensatory effort to retain theta responsivity in the face of declining network activity in this crucial frequency band. Notably, the converse (en- hanced hippocampal theta power in vivo) has been observed following genetic deletion of forebrain HCN1 channels (thereby eliminating sag potentials and shifting the resonance peak to lower frequencies in CA1-PNs) (Nolan et al., 2004).

\section{Input-specific synaptic deficits}

Synaptic conductances dominate network activity measured in the LFP (Buzsáki et al., 2012). Reduced LFP power therefore likely reflects a gross decrease in synaptic innervation of CA1-PNs in $\mathrm{rTg} 4510$ mice, presumably due to tauopathy-mediated synaptic and neuronal degeneration (Ramsden et al., 2005; Spires et al., 2006). This is corroborated by our in vitro recordings demonstrating reduced SC input in $\mathrm{rTg} 4510$ mice (Fig. 6). rTg4510 CA1-PN firing patterns were also significantly altered in vivo (reduced burst firing and theta modulation; Fig. 2), although intracellular recordings revealed comparable firing patterns from both genotypes (Fig. 3). Aberrant rTg4510 CA1-PN activity in vivo therefore likely results from impairments in synaptic drive (rather than alterations to intrinsic membrane properties), an idea supported by recent evidence that attenuated SC transmission reduces CA1-PN burst firing in vivo (Nakashiba et al., 2009).

The functional integration of CA3 (SC) and entorhinal (TA) 
inputs in CA1 is proposed to play a key role in hippocampal processing of spatial information (Ahmed and Mehta, 2009; Carr and Frank, 2012). In line with previous work (Cheng and Ji, 2013), rTg4510 CA1-PNs displayed impaired spatially modulated firing in vivo (Fig. 2). Previous work has suggested that slow gamma oscillations are conveyed to CA1 from CA3, whereas fast gamma oscillations are generated by entorhinal innervation of CA1 (Colgin et al., 2009) and, as such, theta-slow gamma coupling in CAl corresponds to information transfer between CA3-CA1, whereas theta-fast gamma coupling represents entorhinal-CA1 information transfer (Carr and Frank, 2012). Strong coupling between theta and fast gamma oscillations was observed in WT CA1 LFPs, as previously shown during spatially directed behaviors (Chen et al., 2011). In contrast, thetafast gamma coupling was comparatively absent in $\mathrm{rTg} 4510$ mice (Fig. 2), suggesting a deficit in entorhinal-CA1 synaptic signaling.

Our in vitro recordings established that, whereas basal synaptic transmission in the TA pathway was spared in $\mathrm{rTg} 4510$ slices, LTP in this pathway was absent (Fig. 6). Importantly, because $\mathrm{GABA}_{\mathrm{B}}$ receptor-mediated suppression of fast $\mathrm{GABA}_{\mathrm{A}}$-mediated inhibition is known to regulate LTP induction in the TA pathway (Remondes and Schuman, 2003), we also established that GABAergic signaling in this pathway was increased, and the deficits in LTP in rTg4510 slices could be ameliorated by inhibition of GABAergic signaling (Fig. 7). These results suggest that aberrant GABAergic signaling may impair entorhinal-CA1 communication in rTg4510 mice. It is also possible that the deficit in TA LTP arises from changes to the sag potential in rTg4510 CA1PNs. HCN channels that mediate $I_{h}$ are expressed differentially along the somatodendritic axis of CA1-PNs (with higher relative density in distal dendritic compartments) (Magee, 1998) where the TA pathway synapses onto CA1-PNs, and constrain the expression of LTP in the TA pathway (Nolan et al., 2004). Amplification of $\mathrm{I}_{\mathrm{h}}$ in the distal dendrites of rTg4510 CA1-PNs would likely also inhibit the induction of TA LTP.

\section{Translational implications}

Our in vitro data suggest that increased GABA-mediated synaptic inhibition impairs effective synaptic communication between medial entorhinal cortex and CA1 (via the TA pathway). As fast gamma frequency oscillations (Colgin et al., 2009), along with spatial information from grid cells (Hafting et al., 2005), head direction cells (Sargolini et al., 2006), and border cells (Solstad et al., 2008), are conveyed from medial entorhinal cortex to CA1 via the TA pathway, impaired function in this synaptic pathway may contribute to deficits in theta-fast gamma PAC in rTg4510 mice. Cross-frequency coupling in these frequency bands has been linked to both long-term (Tort et al., 2009) and short-term (Canolty et al., 2006) memory, and in particular is thought to play a role in memory retrieval (for extensive review, see Lisman and Jensen, 2013). Therefore, deficits in theta-gamma crossfrequency coupling potentially represent a mechanism by which spatial memory systems malfunction in dementia.

Enhanced inhibition in the dentate gyrus of hippocampus has been observed in transgenic mouse models of Down syndrome (Belichenko et al., 2007, 2009; Kleschevnikov et al., 2012b). For example, in Ts65Dn mice (Davisson et al., 1993), GABA (Kle- $^{-}$ schevnikov et al., 2004) or $\mathrm{GABA}_{\mathrm{B}}$ receptor (Kleschevnikov et al., 2012a) antagonists recover deficits in LTP induction at perforant pathway synapses in a manner comparable with our observations in the TA pathway in $\mathrm{rTg} 4510$ mice, whereas treatment with compounds that decrease $\mathrm{GABA}_{\mathrm{A}}$ (Fernandez et al., 2007; Rueda et al., 2008; Braudeau et al., 2011; Martínez-Cué et al., 2013) and
$\mathrm{GABA}_{\mathrm{B}}$ (Kleschevnikov et al., 2012a) receptor-mediated transmission improve cognitive impairments in Ts65Dn mice. As a result of these findings, a negative allosteric modulator of $\alpha 5$ subunit-containing $\mathrm{GABA}_{\mathrm{A}}$ receptors (which are highly expressed in the proximal and distal dendrites of CA1 pyramidal neurons) (Fritschy and Möhler, 1995; Sperk et al., 1997; Wainwright et al., 2000) has entered clinical trial in Down syndrome subjects (Möhler, 2012), and such compounds may also have therapeutic potential for the treatment of tauopathy-associated dementia.

Neuronal activity is modulated by the dynamic interplay between intrinsic membrane and synaptic conductances (Buzsáki and Draguhn, 2004; Buzsáki and Watson, 2012). Based on the data presented here, it is not possible to establish a causal relationship between the observed cellular, synaptic, and network level changes; this would necessitate longitudinal investigation of multiple time points throughout the time course of tau pathology in this model. Nevertheless, we consider that the phenomena described can be attributed to tauopathy-mediated degeneration of presynaptic and postsynaptic elements. Both our in vitro (attenuated SC input, impaired TA LTP) and in vivo data (decreased extracellular network activity) suggest that synaptic input to CA1-PNs is diminished in $\mathrm{rTg} 4510$ mice, likely resulting from a reduction in axonal and dendritic complexity and therefore fewer functional synapses. As suggested by our mathematical model, a reduction in the dendritic arbor, and therefore capacitance, of CA1-PNs can account for the observed changes in intrinsic membrane properties. Importantly, these synaptic and intrinsic impairments have consequences for the ability of these cells to operate within functional networks in vivo, leading to cognitive deficits (particularly those associated with spatial memory) identified in this mouse model of dementia. Therapies that preserve synaptic and neuronal structure and function by halting degenerative processes early in tauopathy (e.g., tau kinase inhibitors) (Zhang et al., 2013) are therefore likely to be effective in attenuating cognitive impairment in this disease model, and, by extension, in human sufferers of tauopathy-associated dementias. It will also be important for future studies to characterize the ages and staging of tauopathy at which cellular, synaptic, and network changes emerge in rTg4510 mice, and drug-discovery efforts should continue to integrate synaptic, cellular, network, and behavioral assays to quantify disease and treatment mechanisms.

\section{References}

Ahmed OJ, Mehta MR (2009) The hippocampal rate code: anatomy, physiology and theory. Trends Neurosci 32:329-338. CrossRef Medline

Belichenko PV, Kleschevnikov AM, Salehi A, Epstein CJ, Mobley WC (2007) Synaptic and cognitive abnormalities in mouse models of Down syndrome: exploring genotype-phenotype relationships. J Comp Neurol 504: 329-345. CrossRef Medline

Belichenko PV, Kleschevnikov AM, Masliah E, Wu C, Takimoto-Kimura R, Salehi A, Mobley WC (2009) Excitatory-inhibitory relationship in the fascia dentata in the Ts65Dn mouse model of Down syndrome. J Comp Neurol 512:453-466. CrossRef Medline

Bokil H, Andrews P, Kulkarni JE, Mehta S, Mitra PP (2010) Chronux: a platform for analyzing neural signals. J Neurosci Methods 192:146-151. CrossRef Medline

Booth CA, Brown JT, Randall AD (2014) Neurophysiological modification of CA1 pyramidal neurons in a transgenic mouse expressing a truncated form of disrupted-in-schizophrenia 1. Eur J Neurosci 39:1074-1090. CrossRef Medline

Bragin A, Jandó G, Nádasdy Z, Hetke J, Wise K, Buzsáki G (1995) Gamma $(40-100 \mathrm{~Hz})$ oscillation in the hippocampus of the behaving rat. J Neurosci 15:47-60. Medline

Braudeau J, Delatour B, Duchon A, Pereira PL, Dauphinot L, de Chaumont F, Olivo-Marin JC, Dodd RH, Hérault Y, Potier MC (2011) Specific target- 
ing of the GABA-A receptor alpha5 subtype by a selective inverse agonist restores cognitive deficits in Down syndrome mice. J Psychopharmacol 25:1030-1042. CrossRef Medline

Brun VH, Leutgeb S, Wu HQ, Schwarcz R, Witter MP, Moser EI, Moser MB (2008) Impaired spatial representation in CA1 after lesion of direct input from entorhinal cortex. Neuron 57:290-302. CrossRef Medline

Buzsáki G (2002) Theta oscillations in the hippocampus. Neuron 33:325340. CrossRef Medline

Buzsáki G, Draguhn A (2004) Neuronal oscillations in cortical networks. Science 304:1926-1929. CrossRef Medline

Buzsáki G, Watson BO (2012) Brain rhythms and neural syntax: implications for efficient coding of cognitive content and neuropsychiatric disease. Dialogues Clin Neurosci 14:345-367. Medline

Buzsáki G, Anastassiou CA, Koch C (2012) The origin of extracellular fields and currents: EEG, ECoG, LFP and spikes. Nat Rev Neurosci 13:407-420. CrossRef Medline

Canolty RT, Edwards E, Dalal SS, Soltani M, Nagarajan SS, Kirsch HE, Berger MS, Barbaro NM, Knight RT (2006) High gamma power is phaselocked to theta oscillations in human neocortex. Science 313:1626-1628. CrossRef Medline

Carr MF, Frank LM (2012) A single microcircuit with multiple functions: state dependent information processing in the hippocampus. Curr Opin Neurobiol 22:704-708. CrossRef Medline

Chen G, King JA, Burgess N, O'Keefe J (2013) How vision and movement combine in the hippocampal place code. Proc Natl Acad Sci U S A 110: 378-383. CrossRef Medline

Chen Z, Resnik E, McFarland JM, Sakmann B, Mehta MR (2011) Speed controls the amplitude and timing of the hippocampal gamma rhythm. PLoS One 6:e21408. CrossRef Medline

Cheng J, Ji D (2013) Rigid firing sequences undermine spatial memory codes in a neurodegenerative mouse model. eLife 2:e00647. CrossRef Medline

Colgin LL, Denninger T, Fyhn M, Hafting T, Bonnevie T, Jensen O, Moser MB, Moser EI (2009) Frequency of gamma oscillations routes flow of information in the hippocampus. Nature 462:353-357. CrossRef Medline

Crimins JL, Rocher AB, Peters A, Shultz P, Lewis J, Luebke JI (2011) Homeostatic responses by surviving cortical pyramidal cells in neurodegenerative tauopathy. Acta Neuropathol 122:551-564. CrossRef Medline

Crimins JL, Rocher AB, Luebke JI (2012) Electrophysiological changes precede morphological changes to frontal cortical pyramidal neurons in the rTg4510 mouse model of progressive tauopathy. Acta Neuropathol 124: 777-795. CrossRef Medline

Davisson MT, Schmidt C, Reeves RH, Irving NG, Akeson EC, Harris BS, Bronson RT (1993) Segmental trisomy as a mouse model for Down syndrome. Prog Clin Biol Res 384:117-133. Medline

Fernandez F, Morishita W, Zuniga E, Nguyen J, Blank M, Malenka RC, Garner CC (2007) Pharmacotherapy for cognitive impairment in a mouse model of Down syndrome. Nat Neurosci 10:411-413. CrossRef Medline

Fritschy JM, Möhler H (1995) GABAA-receptor heterogeneity in the adult rat brain: differential regional and cellular distribution of seven major subunits. J Comp Neurol 359:154-194. CrossRef Medline

Hafting T, Fyhn M, Molden S, Moser MB, Moser EI (2005) Microstructure of a spatial map in the entorhinal cortex. Nature 436:801-806. CrossRef Medline

Harvey CD, Collman F, Dombeck DA, Tank DW (2009) Intracellular dynamics of hippocampal place cells during virtual navigation. Nature 461 : 941-946. CrossRef Medline

Hodgkin AL, Huxley AF (1952) A quantitative description of membrane current and its application to conduction and excitation in nerve. J Physiol 117:500-544. CrossRef Medline

Hoover BR, Reed MN, Su J, Penrod RD, Kotilinek LA, Grant MK, Pitstick R, Carlson GA, Lanier LM, Yuan LL, Ashe KH, Liao D (2010) Tau mislocalization to dendritic spines mediates synaptic dysfunction independently of neurodegeneration. Neuron 68:1067-1081. CrossRef Medline

Hu H, Vervaeke K, Storm JF (2002) Two forms of electrical resonance at theta frequencies, generated by $\mathrm{M}$-current, $\mathrm{h}$-current and persistent $\mathrm{Na}^{+}$ current in rat hippocampal pyramidal cells. J Physiol 545:783-805. CrossRef Medline

Hutcheon B, Yarom Y (2000) Resonance, oscillation and the intrinsic frequency preferences of neurons. Trends Neurosci 23:216-222. CrossRef Medline

Iqbal K, Liu F, Gong CX, Grundke-Iqbal I (2010) Tau in Alzheimer disease and related tauopathies. Curr Alzheimer Res 7:656-664. CrossRef Medline

Kleschevnikov AM, Belichenko PV, Villar AJ, Epstein CJ, Malenka RC, Mobley WC (2004) Hippocampal long-term potentiation suppressed by increased inhibition in the Ts65Dn mouse, a genetic model of Down syndrome. J Neurosci 24:8153-8160. CrossRef Medline

Kleschevnikov AM, Belichenko PV, Faizi M, Jacobs LF, Htun K, Shamloo M, Mobley WC (2012a) Deficits in cognition and synaptic plasticity in a mouse model of Down syndrome ameliorated by GABAB receptor antagonists. J Neurosci 32:9217-9227. CrossRef Medline

Kleschevnikov AM, Belichenko PV, Gall J, George L, Nosheny R, Maloney MT, Salehi A, Mobley WC (2012b) Increased efficiency of the GABAA and $\mathrm{GABAB}$ receptor-mediated neurotransmission in the Ts65Dn mouse model of Down syndrome. Neurobiol Dis 45:683-691. CrossRef Medline

Langston RF, Ainge JA, Couey JJ, Canto CB, Bjerknes TL, Witter MP, Moser EI, Moser MB (2010) Development of the spatial representation system in the rat. Science 328:1576-1580. CrossRef Medline

Larson J, Wong D, Lynch G (1986) Patterned stimulation at the theta frequency is optimal for the induction of hippocampal long-term potentiation. Brain Res 368:347-350. CrossRef Medline

Lee D, Lin BJ, Lee AK (2012) Hippocampal place fields emerge upon singlecell manipulation of excitability during behavior. Science 337:849-853. CrossRef Medline

Lisman JE, Jensen O (2013) The theta-gamma neural code. Neuron 77: 1002-1016. CrossRef Medline

Magee JC (1998) Dendritic hyperpolarization-activated currents modify the integrative properties of hippocampal CA1 pyramidal neurons. J Neurosci 18:7613-7624. Medline

Martínez-Cué C, Martínez P, Rueda N, Vidal R, García S, Vidal V, Corrales A, Montero JA, Pazos Á, Flórez J, Gasser R, Thomas AW, Honer M, Knoflach F, Trejo JL, Wettstein JG, Hernández MC (2013) Reducing GABAA alpha5 receptor-mediated inhibition rescues functional and neuromorphological deficits in a mouse model of down syndrome. J Neurosci 33: 3953-3966. CrossRef Medline

McGowan E, Eriksen J, Hutton M (2006) A decade of modeling Alzheimer's disease in transgenic mice. Trends Genet 22:281-289. CrossRef Medline

McHugh TJ, Blum KI, Tsien JZ, Tonegawa S, Wilson MA (1996) Impaired hippocampal representation of space in CA1-specific NMDAR1 knockout mice. Cell 87:1339-1349. CrossRef Medline

McNaughton BL, Barnes CA, O'Keefe J (1983) The contributions of position, direction, and velocity to single-unit activity in the hippocampus of freely-moving rats. Exp Brain Res 52:41-49. Medline

Mistry R, Dennis S, Frerking M, Mellor JR (2011) Dentate gyrus granule cell firing patterns can induce mossy fiber long-term potentiation in vitro. Hippocampus 21:1157-1168. CrossRef Medline

Mitra PP, Pesaran B (1999) Analysis of dynamic brain imaging data. Biophys J 76:691-708. CrossRef Medline

Möhler H (2012) Cognitive enhancement by pharmacological and behavioral interventions: the murine Down syndrome model. Biochem Pharmacol 84:994-999. CrossRef Medline

Morris M, Maeda S, Vossel K, Mucke L (2011) The many faces of tau. Neuron 70:410-426. CrossRef Medline

Morris RG, Garrud P, Rawlins JN, O’Keefe J (1982) Place navigation impaired in rats with hippocampal lesions. Nature 297:681-683. CrossRef Medline

Moser EI, Kropff E, Moser MB (2008) Place cells, grid cells, and the brain's spatial representation system. Annu Rev Neurosci 31:69-89. CrossRef Medline

Nakashiba T, Buhl DL, McHugh TJ, Tonegawa S (2009) Hippocampal CA3 output is crucial for ripple-associated reactivation and consolidation of memory. Neuron 62:781-787. CrossRef Medline

Nakazawa K, Sun LD, Quirk MC, Rondi-Reig L, Wilson MA, Tonegawa S (2003) Hippocampal CA3 NMDA receptors are crucial for memory acquisition of one-time experience. Neuron 38:305-315. CrossRef Medline

Nolan MF, Malleret G, Dudman JT, Buhl DL, Santoro B, Gibbs E, Vronskaya S, Buzsáki G, Siegelbaum SA, Kandel ER, Morozov A (2004) A behavioral role for dendritic integration: HCN1 channels constrain spatial memory and plasticity at inputs to distal dendrites of CA1 pyramidal neurons. Cell 119:719-732. CrossRef Medline

Nowacki J, Osinga HM, Brown JT, Randall AD, Tsaneva-Atanasova K (2011) A unified model of CA1/3 pyramidal cells: an investigation into excitability. Prog Biophys Mol Biol 105:34-48. CrossRef Medline 
O’Keefe J, Dostrovsky J (1971) The hippocampus as a spatial map: preliminary evidence from unit activity in the freely-moving rat. Brain Res 34: 171-175. CrossRef Medline

Onslow AC, Bogacz R, Jones MW (2011) Quantifying phase-amplitude coupling in neuronal network oscillations. Prog Biophys Mol Biol 105: 49-57. CrossRef Medline

Peters HC, Hu H, Pongs O, Storm JF, Isbrandt D (2005) Conditional transgenic suppression of $\mathrm{M}$ channels in mouse brain reveals functions in neuronal excitability, resonance and behavior. Nat Neurosci 8:51-60. CrossRef Medline

Ramsden M, Kotilinek L, Forster C, Paulson J, McGowan E, SantaCruz K, Guimaraes A, Yue M, Lewis J, Carlson G, Hutton M, Ashe KH (2005) Age-dependent neurofibrillary tangle formation, neuron loss, and memory impairment in a mouse model of human tauopathy (P301L). J Neurosci 25:10637-10647. CrossRef Medline

Ranck JB Jr (1973) Studies on single neurons in dorsal hippocampal formation and septum in unrestrained rats: I. Behavioral correlates and firing repertoires. Exp Neurol 41:461-531. Medline

Remondes M, Schuman EM (2003) Molecular mechanisms contributing to long-lasting synaptic plasticity at the temporoammonic-CA1 synapse. Learn Mem 10:247-252. CrossRef Medline

Rocher AB, Crimins JL, Amatrudo JM, Kinson MS, Todd-Brown MA, Lewis J, Luebke JI (2010) Structural and functional changes in tau mutant mice neurons are not linked to the presence of NFTs. Exp Neurol 223: 385-393. CrossRef Medline

Rueda N, Flórez J, Martínez-Cué C (2008) Chronic pentylenetetrazole but not donepezil treatment rescues spatial cognition in Ts65Dn mice, a model for Down syndrome. Neurosci Lett 433:22-27. CrossRef Medline

Santacruz K, Lewis J, Spires T, Paulson J, Kotilinek L, Ingelsson M, Guimaraes A, DeTure M, Ramsden M, McGowan E, Forster C, Yue M, Orne J, Janus C, Mariash A, Kuskowski M, Hyman B, Hutton M, Ashe KH (2005) Tau suppression in a neurodegenerative mouse model improves memory function. Science 309:476-481. CrossRef Medline

Sargolini F, Fyhn M, Hafting T, McNaughton BL, Witter MP, Moser MB, Moser EI (2006) Conjunctive representation of position, direction, and velocity in entorhinal cortex. Science 312:758-762. CrossRef Medline

Schmitzer-Torbert N, Jackson J, Henze D, Harris K, Redish AD (2005) Quantitative measures of cluster quality for use in extracellular recordings. Neuroscience 131:1-11. CrossRef Medline

Skaggs WE, McNaughton BL, Wilson MA, Barnes CA (1996) Theta phase precession in hippocampal neuronal populations and the compression of temporal sequences. Hippocampus 6:149-172. CrossRef Medline

Slawinska U, Kasicki S (1998) The frequency of rat's hippocampal theta rhythm is related to the speed of locomotion. Brain Res 796:327-331. CrossRef Medline

Solstad T, Boccara CN, Kropff E, Moser MB, Moser EI (2008) Representation of geometric borders in the entorhinal cortex. Science 322:18651868. CrossRef Medline

Sperk G, Schwarzer C, Tsunashima K, Fuchs K, Sieghart W (1997) GABA(A) receptor subunits in the rat hippocampus: I. Immunocytochemical distribution of 13 subunits. Neuroscience 80:987-1000. CrossRef Medline

Spires TL, Orne JD, SantaCruz K, Pitstick R, Carlson GA, Ashe KH, Hyman BT (2006) Region-specific dissociation of neuronal loss and neurofibrillary pathology in a mouse model of tauopathy. J Pathol 168:1598-1607. CrossRef Medline

Tort AB, Kramer MA, Thorn C, Gibson DJ, Kubota Y, Graybiel AM, Kopell NJ (2008) Dynamic cross-frequency couplings of local field potential oscillations in rat striatum and hippocampus during performance of a T-maze task. Proc Natl Acad Sci U S A 105:20517-20522. CrossRef Medline

Tort AB, Komorowski RW, Manns JR, Kopell NJ, Eichenbaum H (2009) Theta-gamma coupling increases during the learning of item-context associations. Proc Natl Acad Sci U S A 106:20942-20947. CrossRef Medline

Traub RD, Bibbig A, LeBeau FE, Buhl EH, Whittington MA (2004) Cellular mechanisms of neuronal population oscillations in the hippocampus in vitro. Annu Rev Neurosci 27:247-278. CrossRef Medline

Wainwright A, Sirinathsinghji DJ, Oliver KR (2000) Expression of GABA(A) receptor alpha5 subunit-like immunoreactivity in human hippocampus. Brain Res Mol Brain Res 80:228-232. CrossRef Medline

Wills TJ, Cacucci F, Burgess N, O'Keefe J (2010) Development of the hippocampal cognitive map in preweanling rats. Science 328:1573-1576. CrossRef Medline

Witton J, Staniaszek LE, Bartsch U, Randall AD, Jones MW, Brown JT (2014) Disrupted hippocampal sharp-wave ripple-associated spike dynamics in a transgenic mouse model of dementia. J Physiol. Advance online publication. Retrieved Dec. 5, 2014. doi: 10.1113/jphysiol.2014.282889. CrossRef Medline

Zhang X, Hernandez I, Rei D, Mair W, Laha JK, Cornwell ME, Cuny GD, Tsai LH, Steen JA, Kosik KS (2013) Diaminothiazoles modify Tau phosphorylation and improve the tauopathy in mouse models. J Biol Chem 288: 22042-22056. CrossRef Medline 